\title{
Grazer behavior can regulate large-scale patterning of community states
}

\author{
Vadim A. Karatayev ${ }^{1,2,3}$, Marissa L. Baskett ${ }^{1}$, David J. Kushner ${ }^{4}$, Nicholas T. \\ Shears $^{5}$, Jennifer E. Caselle ${ }^{6}$, Carl Boettiger ${ }^{7}$ \\ 1 - Department of Environmental Science and Policy, University of California, Davis, USA \\ 2 - Graduate Group in Ecology, University of California, Davis, USA \\ 3 - School of Environmental Sciences, University of Guelph, Guelph, Canada \\ 4 - Channel Islands National Park, Ventura, USA \\ 5 - Leigh Marine Laboratory, Institute of Marine Science, University of Auckland, \\ Auckland, New Zealand \\ 6 - Marine Science Institute, University of California Santa Barbara, Santa Barbara, USA \\ 7 - Department of Environmental Science, Policy and Management, University of \\ California, Berkeley, USA \\ * - corresponding author. 2004 Wickson Hall, One Shields Ave, University of California, \\ Davis, 95616. vkaratayev@ucdavis.edu.
}

Authorship statement: VAK and MLB conceived the study; VAK took the lead on designing the approach, performing the analysis and writing the manuscript, with substantial input from all authors.

\section{Abstract}

Ecosystem patterning can arise from environmental heterogeneity, biological feedbacks that produce multiple persistent ecological states, or their interaction. One source of feedbacks is density-dependent changes in behavior that regulates species interactions. By fitting dynamical models to large-scale $(\sim 500 \mathrm{~km})$ surveys on temperate rocky reefs, we find that behavioral feedbacks best explain why kelp and urchin barrens form either reef-wide patches or local mosaics. Best-supported models in California include feedbacks where starvation intensifies grazing across entire reefs create reef-scale, alternatively stable kelp- and urchindominated states (39\% of sites). Best-fitting models in New Zealand include the feedback of urchins avoiding dense kelp stands that can increase abrasion and predation risk, which drives a transition from shallower urchin-dominated to deeper kelp-dominated zones, with patchiness at 3-8m depths with intermediate wave stress. Connecting locally-studied processes with region-wide data, we highlight how behavior can explain community patterning and why some systems exhibit community-wide alternative stable states.

Keywords: Behavior, kelp forests, alternative stable states, dynamical models, spatial patterning 


\section{Introduction}

Spatial patterning in community types characterizes many ecosystems. For example, in arid ecosystems patches of shrubs and barren soil $25 \mathrm{~m}$ in diameter form mosaic patterns (Klausmeier 1999). On mountain ranges, strips of ribbon forests 200-500m wide intersperse with wider bands of grassy meadows (Hiemstra et al. 2006). In lakes, turbid-water states with high algal densities dominate fertilized lake basins 5-10km long while less polluted basins remain in a clear-water state characterized by aquatic vegetation (van den Berg et al. 1998). A longstanding focus of empirical and theoretical work has aimed to resolve the processes generating ecosystem patterns and their spatial scale.

Spatial patterning may occur due to underlying environmental heterogeneity, local biological feedbacks, or an interactive combination of both drivers (Rietkerk \& Van de Koppel 2008). Examples of environment-driven patterns include gradients in desiccation stress that zone intertidal communities from heat-tolerant to more sensitive species with increasing water depth (Dayton 1971), and, in forests, zonation from more competitive to more droughttolerant plant species along rainfall gradients (Whittaker 1960). Patterning can also arise when biological feedbacks reinforce distinct ecological states. If interactions change from positive to negative with distance between individuals, self-organized patterns of populated and empty areas occur in homogeneous environments (Rietkerk \& Van de Koppel 2008). For example, one possible source of mosaics in arid ecosystems is that shrubs collect water from surrounding soil, facilitating their immediate neighbors but competing with more distant plants (Klausmeier 1999). Tree stands analogously displace growth-inhibiting snow into adjacent meadows, a process that could explain emergent ribbon patterns in alpine forests (Hiemstra et al. 2006). If feedbacks do not change sign with distance, they can interact with environmental heterogeneity to drive patterns over large scales. For instance, grasses predominate in areas of low-moderate herbivory by dissipating grazing across many plants but collapse to a low-density state from overgrazing in areas with high livestock densities (NoyMeir 1975). In all cases feedback-induced patterning requires strong and often nonlinear species interactions.

One possible driver of biological feedbacks is density-dependent changes in behavior (Peckarsky et al. 2008). In predator-prey stream systems, behavioral avoidance of trout can reduce mayfly herbivory by $90 \%$ (McPeek \& Peckarsky 1998). Concomitantly, abundant prey can reduce predation by sharing social information within and across prey species (Gil et al. 2018). On coral reefs, for instance, activity of herbivorous fishes as part of large groups that reduce predation risk can account for $68 \%$ of total consumption (Gil \& Hein 2017), and influence the potential for coral-dominated or algal-dominated community states (Gil et al. In review). Density-dependent changes in behavior could also create biological feedbacks, for instance when dense plant aggregations increase predation risk and decrease herbivory, feeding back to increase local plant recruitment. This forms one possible mechanism expanding aspen stands following wolf re-introduction in Yellowstone National Park (Fortin et al. 2005). This predicted potential for density to feed back and affect biological interactions through behavior raises the question of whether behavior can also underpin observed, large-scale community patterning. 
Temperate rocky reefs exemplify each of patterned communities, behavior-mediated herbivory, and environmental variation. Patterning of two distinct ecological states in these ecosystems, kelp forests and urchin-dominated barrens (Fig. 1a, c), can occur at drastically different scales in different regions. Whereas large-scale $(>1 \mathrm{~km})$ barrens and forests span all depths on California reefs (Fig. 1d; Cavanaugh et al. 2014), in New Zealand meter-scale patchiness occurs at intermediate depths while kelp occupy deeper water and urchins shallower zones (Fig. 1b, Grace 1983; Parsons et al. 2004; Leleu et al. 2012). This difference in patchiness scales might arise from a greater sensitivity of the dominant kelp species in New Zealand to wave stress in shallow areas compared to the much larger giant kelp species dominant in California. However, these regions may also differ in the roles of behavioral feedbacks controlling urchin grazing activity. In New Zealand, grazing might intensify in local patches where kelp densities are insufficient to deter urchins via physical abrasion (Konar 2000) or by attracting predators (Fig. 2c; Cowen 1983). In California, where giant kelp cause little abrasion but form much larger surface canopies, grazing can instead increase synchronously across the reef when low kelp densities lead to insufficient subsidies of kelp fronds drifting to urchins on the seafloor, causing urchin starvation (Ebeling et al. 1985; Harrold \& Reed 1985). The ability of biological feedbacks and distinct states to explain temperate reef spatial patterning would also inform whether urchin barrens and kelp forests occur as alternative stable states, a long-debated phenomenon in rocky temperate reefs (Petraitis \& Dudgeon 2004).

To test whether or not behavior can affect large-scale community patterns, here we compare the relative roles of environmental variation, urchin densities, and urchin behavior in kelp spatial patterning. Specifically, we compare how well dynamical models incorporating each feature, alone and in combination, can explain field data. Our results show that environment and kelp-density-mediated behavior feedbacks best explain observations assembled across hundreds of California and New Zealand reefs. Analyzing our best-fitting models, we then show that behavior-driven alternative stable states can occur as local mosaics in New Zealand or span entire reefs in California.

\section{Methods}

\section{$2.1 \quad$ Study systems}

We focus our analysis on temperate rocky reefs in Northeast New Zealand (NZ) and the California Northern Channel Islands (CA) dominated by kelp (Macrocystis pyrifera, CA, and Ecklonia radiata, NZ) or urchins (Strongylocentrotus purpuratus, Mesocentrotus franciscanus in CA and Evechinus chloroticus in NZ). Like many temperate reefs, fast kelp growth and intense urchin grazing characterize these systems: abundant urchins can denude kelp forests in weeks, while under low urchin densities kelp can recolonize barrens within a few months (Ebeling et al. 1985). In contrast, urchin populations experience lower turnover and fluctuate more gradually in response to urchin predator abundance and multi-year changes in ocean climate (Shears et al. 2012; Okamoto 2014). This difference in time scales means that kelp abundance and urchin grazing activity can reach steady state under a given urchin density, whereas urchin density depends little on local kelp abundance due to demographic openness 
(Okamoto 2014) and can remain high in the absence of kelp (Filbee-Dexter \& Scheibling 2014; Ling et al. 2015).

Urchin grazing activity can substantially decline with either local- or reef-scale kelp density (Dayton 1985b). Urchins typically remain in rock crevices that offer refuge from storms and predators, consuming only kelp fronds detached from plants by waves and carried to the bottom by currents over 100-1000m ('drift kelp' hereafter; Ebeling et al. 1985; Harrold \& Reed 1985). When this long-distance subsidy becomes insufficient, low kelp and high urchin densities feed back to increase grazing across the reef as starving urchins emerge from refugia and graze on kelp plants directly (Dayton 1985b). More locally, dense stands of kelp can physically abrade urchins as plants move with waves (Konar 2000) and shelter urchin predators that lead to cryptic behavior (Cowen 1983); through both mechanisms declining kelp density within a stand feeds back to further increase local grazing. Feedbacks at either scale can theoretically create alternatively stable community states with resources either abundant or sparse (Bate \& Hilker 2014).

\section{$2.2 \quad$ Data}

We use surveys of kelp density spanning 200-300km coastlines in each region, with 71 reefs sampled in 2001 in New Zealand (Shears \& Babcock 2004) and 93 reefs sampled over 5-30 years in California (Kushner et al. 2013; Caselle et al. 2018). This geographic extent allows us to disentangle the effects of multiple processes by sampling a wide range of environments and increases robustness of our results to inter-annual variation in environment by exceeding the spatial scales of storms, upwelling variability, or recruitment pulses (8-50km; Cavanaugh et al. 2013; Karatayev \& Baskett 2020). Long-term data on California reefs (5-30 years) additionally allows us to verify our assumption that kelp reach steady states within a single year (see "Role of behavioral feedbacks" below).

Samples in both systems were collected at the end of the kelp growing season (JulyAugust in CA, March-June in NZ) and span 100-500m² of each reef $s$ (see Appendix A for details on dataset and sampling methodologies). At the reef scale, we account for potential environmental drivers of kelp dynamics, including: total urchin predator density $P_{s}$ (Shears et al. 2008; Caselle et al. 2018), wave stress $E_{s}$ (Cavanaugh et al. 2011), and temperaturedriven nitrate concentration $G_{s}$. In preliminary fits, however, we did not find an effect of nitrate limitation on kelp density and so omit it from the model below (see Appendix A). Each reef was sampled using transects with 15-50 1-20m² samples spanning a $\sim 15 \mathrm{~m}$ water depth gradient (2,018 NZ samples, 16,539 CA samples). While Ecklonia can inhabit shallower depths than Macrocystis, in New Zealand we omitted 228 shallow $(<3 \mathrm{~m})$ samples where wave-tolerant algae displaced both Ecklonia and urchins (Appendix A); we also omitted 777 samples along continuous transects that recorded Ecklonia presence but not density. Data collected in each quadrat $q$ include densities of adult kelp and urchins ( $>25 \mathrm{~mm}$ test diameter, $U_{q}$ ), water depth $Z_{q}$ (which attenuates waves), and near-bottom light availability $L_{q}$. 


\subsection{Model description}

Our model follows dynamics of adult kelp abundance $N_{q}$ in 1-5 $\mathrm{m}^{2}$ locations $q$ across a $0.1-0.5 \mathrm{~km}^{2}$ reef $s$ (Fig. 2a). We model kelp reproduction, spore survival, and adult survival as they depend on either local kelp density or kelp density averaged across the reef $N_{s}=$ $k^{-1} \sum_{q=1}^{k} N_{q}$, depending on the process and behavioral assumptions. Likewise, environmental factors (Table S1) are either homogeneous across the reef (juvenile kelp survival, predators) or vary among samples (urchins, wave stress, light). This model structure can produce kelp- and urchin-dominated regimes that form localized mosaics, gradients along depthdependent environmental factors, or one regime spanning an entire reef. Below we describe the full model with all drivers, where zeroing out individual dynamics yields sub-models with different driver combinations.

Kelp reproduce continuously during the year with a baseline fecundity $m$. Newly produced spores can disperse over short distances $(<500 m$ for Macrocystis, Anderson \& North 1966; Reed et al. 1992). Therefore, we model the density of spores arriving in a location $q$ as (1) the proportion $\gamma$ of all spores dispersing throughout the reef plus (2) the proportion $1-\gamma$ of locally-produced spores dispersing $<5 \mathrm{~m}$. Thus, the total amount of spores $r$ that arrive in location $q$ following dispersal is

$$
r\left(N_{q}, N_{s}\right)=m\left(\gamma N_{s}+(1-\gamma) N_{q}\right)
$$

Survival of settled zygotes into adult sporophyte stages depends on both local and reefscale factors. First, we assume light availability increases with measured visibility $L_{q}$ given proportionality constant $g_{L}$ and declines with local density dominant adults $N_{q}$ given proportionality constant $d$ (Dayton 1985b). Due to their greater palatability compared with adults, juveniles also experience high rates of urchin grazing $\delta_{R}$ proportional to local urchin density $U_{q}$, which can depend on behavioral responses to kelp density according to the function $b\left(N_{x}\right)$, as described below. On the reef scale, we account for environmentally-driven stochasticity in survival (e.g., as might be due to thermal stress or interspecific competition) using a log-normally distributed random variable $\Omega_{R}$. Finally, given fast maturation (2-3 mo.) and high sensitivity of juveniles to competition and grazing, we assume juvenile abundance quickly reaches steady state on the time scale of adult kelp abundance, so that overall recruit survival is

$$
S_{R}\left(N_{q}, N_{x}\right)=\frac{\Omega_{R}\left(1-g_{L}+g_{L} L_{q}-d N_{q}\right)}{1+\delta_{R} U_{q} b\left(N_{x}\right)} .
$$

Adult mortality depends on local-scale urchin grazing and wave stress $E_{s}$. We model reduced wave stress dissipation by depth $Z_{q}$ at more exposed sites following Bekkby et al. (2008). This relationship depends on region-specific oceanographic features, represented by $f_{w}$ and scaling factor $\mu$. Adult mortality to wave stress is then

$$
w\left(E_{s}, Z_{q}\right)=\mu E_{s} \exp \left(-f_{w} Z_{q} E_{s}^{-1}\right) .
$$

Grazing on adults occurs at a per-urchin rate $\delta_{A}$, and as with recruit survival can additionally depend on behavior according to $b\left(N_{x}\right)$. Thus, per-capita adult mortality from grazing is

$$
\nu_{A}\left(N_{x}\right)=\delta_{A} U_{q} b\left(N_{x}\right) .
$$


For kelp mortality from grazing, we assume urchin density is constant on the time scale of annual kelp dynamics but grazing rate can dynamically depend on adult kelp density ('behavior feedbacks' hereafter). We model grazing activity declining at high densities using a per-kelp grazing inhibition factor $\xi_{A}$ in a generic 'Type IV' functional response that represents emergent prey or resource defense (Koen-Alonso 2007; Bate \& Hilker 2014). Dependence of this function on local-scale kelp density $N_{x}=N_{q}$ represents local-scale feedbacks involving physical abrasion, as we expect to be the case for New Zealand, and dependence on reefscale kelp density $N_{x}=N_{s}$ represents reef-scale feedbacks where drift kelp availability affects cryptic urchin behavior and associated direct grazing on kelp, as we expect to be the case for California. Urchins may additionally avoid active grazing on reefs with high predator abundance $P_{s}$. Given a per-predator grazing inhibition rate $\xi_{P}$, we integrate this inhibition over the entire year to arrive at the fractional decline in grazing due to density-dependent predator avoidance, $\exp \left(-\xi_{P} P\right)$ (see Appendix D for separating predator effects on density versus behavior). Altogether, behavior-mediated decline in urchin grazing is

$$
b\left(N_{x}\right)=\frac{\exp \left(-\xi_{P} P\right)}{1-\xi_{A} N_{x}^{2}}
$$

The overall dynamics of local kelp abundance are then

$$
\frac{d N_{q}}{d t}=r\left(N_{q}, N_{s}\right) S_{R}\left(N_{q}, N_{x}\right)-w\left(E_{s}, Z_{q}\right) N_{q}-\nu_{A}\left(N_{x}\right) N_{q}
$$

\subsection{Model analyses}

To compare the role of each potential driver (environmental, urchin density, behavioral), we compare the best fit of the full model (Eqn. 4) and simpler models that omit the effects of environmental factors $\left(\mu=g_{L}=0\right)$, grazing $\left(\delta_{i}=0\right)$, urchin predator avoidance $\left(\xi_{P}=0\right)$ and kelp-density behavior feedbacks $\left(\xi_{A}=0\right)$, each individually and in combinations. We fit model parameters to all data in each region. Given that samples were collected at the end of the growing season and high kelp growth rate (see "Study system" above), we assume populations reach steady state within a year and fit model equilibria to observed kelp abundance. We test this assumption by quantifying differences between end-of-year and equilibrium kelp abundance in best-fitting models (Appendix B). Our approach additionally assumes that kelp densities are independent among years, which may be less likely if disturbances severely deplete populations; we test this assumption using time-series-based model fits in California (Appendix C), where ocean climate extremes and recruitment pulses of the shorter-lived $S$. purpuratus urchin occur more frequently compared to New Zealand.

To evaluate model performance, we first numerically integrate each model to steady state on each reef under observed covariates using a Runge-Kutta method in R 3.4.3 (R Core Team 2017, deSolve package), with initial kelp abundance across the reef initially high or low (80th and 5th percentiles of observed densities in samples with kelp). Low initial abundance can occur when senescence pulses (in NZ) or storms (in CA; Cavanaugh et al. 2011) precede the growing season. To account for a range of possible recruitment conditions over the preceding year, we additionally solve the model under 30 realizations of $\Omega_{R}$ (Fig. 2c). Rather than 
fitting the distribution of $\Omega_{R}$, we set the mean to 1 and standard deviation $\sigma_{R}=0.35$ based on year-long recruitment experiments (Moreno \& Sutherland 1982) because outlying kelp density observations favored maximal $\sigma_{R}$ values. We then compare predicted densities with counts in a quadrat using Poisson likelihood, averaged across the 60 model realizations. Summing across all samples in the region, we arrive at the total model likelihood under a given parameter set. We then find the best-fitting parameter sets using the DIRECT (global) followed by COBYLA (local) optimization algorithms in nloptr (Jones et al. 1993; Johnson 2019) and compare models based on Bayesian Information Criterion differences $(\Delta B I C)$, where $\Delta \mathrm{BIC}>4$ indicates improved model fit (Bolker 2008). Note that in California we fit models to data across all years; we found analogous results in preliminary analyses using a single sampling year from each reef.

To resolve how grazing and wave stress gradients can jointly pattern communities, we use the best-fitting models from each region to project predicted kelp abundance over the observed range of reef-scale urchin densities. Within each reef we simulate 30 locations spanning the sampled depth range. Throughout, we set urchin distribution across depths and reef-scale wave stress, light availability, and predator density to the average values observed in data. We compare model projections with observed kelp patterns smoothed using 2-D splines.

To evaluate the role of behavior in explaining specific aspects of observed community patterns, we compare survey results with predictions of our best-fitting models with and without behavioral feedbacks. For this we first categorize the community state in each sample and model prediction (Fig. 1a, c). We classify samples and predictions with urchins and few kelp (CA: $<0.05$ individuals $m^{-2}, \mathrm{NZ}:<0.5$ individuals $m^{-2}$ ) as urchin-dominated, and classify all other samples as kelp-dominated. For reef-scale patterns, we examine the extent to which steady-state kelp presence, averaged across all depths, depends on whether kelp are initially abundant or rare. For local patterning within reefs, we then use a subset of data collected along contiguous transects (777 NZ samples, 5,644 CA samples) and quantify patch sizes as the number of adjacent samples with the same community regime.

\section{Results}

\subsection{Role of urchin behavior}

Behavior-mediated grazing in California Channel Islands and an interactive effect of behavior-mediated grazing and environmental variation in Northeast New Zealand predominantly explain patterns in field data (Table 1). Best-fitting models in both regions include all three of environment, grazing, and behavior, and explain much of the variation in kelp occurrence across all samples $\left(\mathrm{NZ} \mathrm{R}^{2}=0.55\right.$; $\left.\mathrm{CA} \mathrm{R}^{2}=0.43\right)$. In models with behavior, localscale grazing feedbacks (i.e., kelp-density-mediated grazing) in New Zealand and reef-scale grazing feedbacks in California best explain the data (Table 1). In California, models with grazing and behavioral feedbacks only outperform models with grazing and environmental factors only (difference in $\mathrm{BIC}=2889$ ). This contrasts New Zealand, where models with environmental factors alone better explain the data than models with only grazing and behavior $(\triangle \mathrm{BIC}=80)$; however, a model incorporating all three processes greatly outperforms all other 
models $(\triangle \mathrm{BIC} \geq 338)$. In both regions, models with behavior feedbacks outperform models without behavior because they can explain the co-occurrence of high and low kelp densities at intermediate urchin densities (Fig. 3). Identical model ranking and comparable parameter estimates occur in time-series-based model fits in CA, despite the stronger temporal variation in abiotic conditions and urchin densities in this region (Appendix $\mathrm{C}$ ).

In both regions behavior improved model fit predominantly through kelp-density feedbacks as compared to predator-density feedbacks. Models with environment and kelpdensity-mediated behavior outperformed models with environment and predator-densitymediated behavior ( $\mathrm{CA} \triangle \mathrm{BIC}=7685$; $\mathrm{NZ} \triangle \mathrm{BIC}=338$ ). Nevertheless best-fit declines in grazing via predator avoidance appeared strong (up to $60 \%$ of from grazing in $\mathrm{CA}, 40 \%$ in $\mathrm{NZ}$ ) and improved model fit in both regions ( $\mathrm{CA} \Delta \mathrm{BIC}=1614$; $\mathrm{NZ} \Delta \mathrm{BIC}=6$ ), with lower support for predator avoidance in New Zealand possibly arising because few reefs had abundant predators.

\subsection{Drivers of community patterning}

The local scale of behavioral feedbacks, combined with a decline in wave stress with depth, best explains the much smaller scale of community patterning in New Zealand than in California. In New Zealand, our best-fitting model predicts barrens as the only stable state in shallow areas $(<3 m)$ due to a combination of grazing and high wave stress (Fig. $4 \mathrm{~b})$. At greater water depths that largely attenuate waves $(>8 m)$, we predict forests are the only stable state because kelp quickly form dense stands that inhibit grazing. At intermediate wave stress between these zones, we predict that alternative stable states span $1-5 \mathrm{~m}^{2}$ patches, where urchins concentrate grazing outside of dense kelp stands. This interface occurs at greater depths and urchin barrens cover a larger fraction of the system on reefs with greater overall urchin densities. In California, we predict that community regimes simultaneously span all reef depths due to the larger scale of grazing feedbacks (Fig. 4d, Table 1).

\subsection{Presence of alternative stable states}

Our best-fitting models predict that alternative stable states can occur in both regions (39\% of CA samples, $29 \%$ of NZ samples, Figs. 3, 4b, d). In California, alternative stable states can occur at the scale of entire reefs (Fig. 5b, d; predicted for all samples at $39 \%$ of CA reefs). In New Zealand, alternative stable states occur over only a narrow range of depth-dependent wave stress intensities, such that our best-fitting model predicts that the final reef state depends little on initial kelp abundance (Fig. 5a). In this region, the small scale of kelp- and urchin-dominated patches observed in data arise only in models with localscale behavior feedbacks (Fig. 5c). This shows that the spatial scale of behavioral feedbacks can determine the scale of patterning when feedbacks produce alternative stable states.

\section{Discussion}

Our results show that behavior can determine the presence and scale of community patterning by mediating consumer-resource interactions in temperate rocky reefs. This potential 
occurs through feedbacks where density-dependent changes in behavior amplify consumption when resources decline. In heterogeneous environments, the scale of this feedback determines the spatial extent of the resulting resource- or consumer-dominated community regimes. Specifically, we find that kelp forests and urchin barrens spanning entire reefs in California Channel Islands are most consistent with large-scale feedbacks, as might occur when drift kelp are transported over large distances and starvation-induced active grazing occurs when kelp densities decline across entire reefs (Figs. 4d, 5b; Table 1; Harrold \& Reed 1985). In contrast, in Northeast New Zealand feedbacks that deter grazing locally, as might occur when kelp stands increase predation or physical abrasion (Ebeling et al. 1985; Konar 2000), can explain fine-scale patterning of community regimes organized into distinct depth zonation by a gradient in wave stress (Figs. 4b, 5a). Models with environmental gradients but no behavioral feedbacks do not predict these patterns (Table 1, Figs. 3, 5). Thus, we show that feedbacks in consumer behavior can pattern communities by interacting with environmental heterogeneity and by generating alternative stable states at specific scales.

Our findings are consistent with two types of behavioral feedbacks that might produce patterning within and beyond kelp systems: starvation-induced consumption and group defense. Starvation-induced active urchin grazing might create persistent patterns observed in California because, after overgrazing kelp, urchins can survive for decades with little food due to low metabolic costs (Filbee-Dexter \& Scheibling 2014; Ling et al. 2015). In homeothermic taxa or in warmer systems, prolonged starvation can cause grazer mortality or emigration which allow resource recovery. Long-term, such dynamics can produce consumerresource cycles, which may additionally propagate across space as grazing fronts in systems where consumers can move freely (Sinclair 1977; Lauzon-Guay \& Scheibling 2007; Silliman et al. 2013). Conversely, persistent patterning of sparse and abundant resources, as in New Zealand reefs, can arise when abundant prey or plants exhibit group defense that shifts predation or herbivory to less defended species or to locations where resources are sparse (Schneider \& Kefi 2016). Group defense can arise through resource behavior when prey share information about predators (Gil et al. 2018) or form herds or, alternatively, through consumer behavior when herbivores avoid increased predation risk (Laundré et al. 2001) or environmental stress (Konar 2000) in dense vegetation. Taken together, behavioral feedbacks might be more likely to drive persistent community patterns when they arise through group defense than via starvation-induced consumption.

In addition to abundant kelp reducing grazing rates through behavioral feedbacks as modeled here, abundant resources can also reduce per capita mortality by diluting herbivory among numerous plant individuals (Scheffer et al. 2008). This dilution feedback can occur in many systems where consumers have limited grazing rates and consumer density predominantly depends on conditions during critical periods or life stages rather than on resource abundance. Strong dilution feedbacks can produce alternatively stable consumeror resource-dominated states in an array of systems such as pastures (Noy-Meir 1975), coral reefs (Mumby et al. 2007), and lakes (Downing et al. 2012). Multiple feedbacks co-occurring in the same system, such as behavior- and dilution-driven feedbacks, can produce alternative stable states synergistically even when individually each feedback is insufficient to do so (van de Leemput et al. 2016). 


\subsection{Community patterning on temperate rocky reefs}

While we fit models to New Zealand and California data, our findings can inform the drivers of community patterns in temperate rocky reefs globally. Large drift subsidies from canopy-forming kelp could underlie reef-scale grazing feedbacks and patchiness along the North American west coast, except where grazing has weaker effects on kelp due to greater storm disturbance (e.g., central California, Cavanaugh et al. 2011), heat stress (southern and Baja California, Bell et al. 2018), urchin disease (Lafferty 2004), and predator densities (e.g., marine protected areas, Hamilton \& Caselle 2015). Similarly, on Macrocystis-dominated reefs of central Chile, urchins rely primarily on passive grazing (Vásquez et al. 1984) but in other areas can form barrens. A second reef-scale feedback that can contribute to reef-scale forests and barrens arises when kelp facilitate recruitment of urchin predators (Karatayev \& Baskett 2020), which freely forage across entire reefs (Topping et al. 2005). Our results highlight that behavior might strengthen this feedback by detecting declines in grazing activity with predator density in both regions, complementing analogous findings in California (Ebeling et al. 1985; Caselle et al. 2018).

Mosaics separating urchin- and kelp-dominated depth zones found in New Zealand (Fig. $1,4 \mathrm{~b}, 5 \mathrm{c}$ ) also occur in other systems dominated by sub-canopy kelp species, including northern Chile (Vásquez \& Buschmann 1997), South Africa, (Ling et al. 2015), and Nova Scotia (Dayton 1985a). Compared to canopy-forming kelp, sub-canopy kelp might reduce long-distance drift subsidies through lower total biomass (here, $0.05 \mathrm{~kg} \mathrm{~m}^{-2}$ in NZ vs. $2 \mathrm{~kg}$ $\mathrm{m}^{-2}$ in CA; Shears \& Babcock 2004; Cavanaugh et al. 2011) but increase short-distance urchin deterrence (e.g. 'whiplash', sheltering predators) because shorter plants move more with waves and concentrate biomass near the bottom. Ubiquitous depth gradients in wave stress might also be greater in sub-canopy compared to canopy-forming kelps because subcanopy species can inhabit more exposed $(<2 \mathrm{~m})$ depths while simultaneously being largely sheltered from wave stress in deeper $(>10 \mathrm{~m})$ areas. However, kelp-urchin zonation may be reversed with barrens forming in deeper habitats when urchins are more sensitive to wave action than kelp (e.g., Chile, Nova Scotia; Dayton 1985a).

\subsection{Model assumptions}

To avoid model over-fitting, our approach leaves out additional potential dynamics that might drive alternative stable states and therefore patchy spatial patterning in temperate rocky reefs. First, we do not consider competition among primary producers which might displace competitively inferior juvenile stages of Ecklonia and Macrocystis, although $<10 \%$ of samples indicate competitive exclusion by lacking both kelp and urchins (Fig. 1). Second, in our focus on whether or not behavior can explain observed patterns, we ignore many additional feedbacks hypothesized to drive (alone or in combination) alternative stable states in kelp forests (Ling et al. 2015). These additional feedbacks could increase the potential for patchiness. Finally, seasonality in wave-induced mortality (predominantly in winter) and recruitment (predominantly in spring) might weaken our assumption that kelp abundance reaches steady state within a year. Seasonality-driven transients can obscure distinct equilibria (Mumby et al. 2013) and cause under-estimation of alternative stable states. 
We also omit several secondary urchin behaviors that in both regions can increase the role of behavioral feedbacks in particular. Available data likely underestimates California urchin densities because cryptic urchins are harder to detect, causing best-fit models to underestimate the role of behavior in limiting grazing. Our model also omits urchin movement across the reef in response to kelp density, which can produce moving or stationary grazing fronts (Silliman et al. 2013; Filbee-Dexter \& Scheibling 2014) and in New Zealand might explain higher urchin densities in shallower areas. However, how kelp affects urchin movement in New Zealand is unclear because barrens do not expand following regular Eklonia senescence pulses. Given the strong role of behavior in community patterning found here, we suggest future experiments and more detailed spatial models explore the drivers of urchin movement.

\subsection{Detection of alternative stable states}

Behavioral feedbacks drive patchy spatial patterning in our best-supported models by giving rise to alternative stable states. Therefore, our results support the relevance of this phenomenon across both regions, especially in California given the greater frequency of samples with alternative stable states ( $39 \%$ versus $29 \%$ in NZ, Table 1 ). Greater prevalence in California is partly due to regional differences in feedback scale, with more local feedbacks in New Zealand limiting alternative stable states to reef depths with intermediate wave stress on kelp (Fig. 4). These localized states average out to produce a gradual reef-wide response to changes in urchin density and little-to-no dependence of reef state on initial kelp abundance in New Zealand, while large-scale feedbacks in California produce alternative stable states spanning entire reefs (Fig. 5). This result supports existing theory (van Nes \& Scheffer 2005) predicting greater relevance of alternative stable states at ecosystem scales either in spatially homogeneous environments or when biological feedbacks span large scales by involving mobile matter (e.g., drift kelp) or organisms (e.g., urchin predators).

The region-specific scales of alternative stable states found here can also help explain the debated presence of this phenomenon on temperate rocky reefs. However, empirically demonstrating alternative stable states or long-term transients with a single stable state is challenging because of the limited spatial and temporal scales of experimental manipulations and measurements of biological feedbacks (Petraitis \& Dudgeon 2004). Our results suggest one explanation for this debate: that the scale of alternative stable states varies among regions (Fig. 5). We suggest that future studies and syntheses estimate the potential scale of alternative stable states by quantifying the smallest observed areas of each state or the spatial scale of underlying ecological feedbacks.

Our analysis additionally expands on previous approaches to detecting alternative stable states. Studies most commonly test for this phenomenon based on whether distinct ecological states (e.g., Fig. 5b) or initial-condition dependency occur under the same levels of an environmental driver (Petraitis 2013; Mumby et al. 2013) by pooling observations or experiments across space or time. However, environmental heterogeneity may obscure distinct stable states (Mumby et al. 2013): for instance, our best-fit models predict that kelp densities in forested states double from 5 to $10 \mathrm{~m}$ depths (Fig. 4b). Fitting dynamical models to time series can explicitly account for the expected effects of environmental variation (e.g., Ives et al. 2008), but requires long-term monitoring data. Instead, here we fit model steady states 
to data from large spatial surveys. Following Ling et al. (2015), our analysis utilizes time scale differences between kelp abundance and comparatively slow changes in environment and urchin abundance, producing model ranking analogous to time-series-based analyses (Appendix C). While this approach assumes that ecological interactions not modeled or measured explicitly vary little across locations and time, hierarchical modeling and model averaging (Bolker 2008) techniques can account for spatiotemporal variation implicitly. Altogether, our work highlights how combining spatial surveys, mechanistic dynamical models, and statistics can predict the likelihood, given uncertainty and variable environments, that alternative stable states underlie observed ecological patterns.

\section{Acknowledgments}

We would like to thank Alan Hastings and Jay Stachowicz for feedback that improved the model and manuscript and Stephen Ellner for insights on model fitting. We also thank Tom Bell and Kevin Lafferty for access to oceanographic data. Funding for this project was provided by the National Science Foundation Graduate Research Fellowship and the Davis-Auckland Graduate Student Exchange grant to VAK. 
bioRxiv preprint doi: https://doi org/10,1101/722215; this version posted August 24,2020 . The copyright holder for this preprint (which was not certified by peer review) is the author/funder, who has granted bioRxiv a license to display the preprint in perpetuity. It is made available under aCC-BY-NC-ND 4.0 International license.

Figure 1: Patterns of kelp and urchin density in New Zealand (a, b) and California (c, d). (a, c) Region-specific distribution of kelp- and urchin-dominated states with $\mathrm{N}$ indicating total numbers of samples. Dashed lines in $(\mathrm{a}, \mathrm{c})$ denote kelp threshold densities used to categorize community regimes as forested (for $>0.5$ ind. $\mathrm{m}^{-2}$ in NZ and $>0.05$ ind. $\mathrm{m}^{-2}$ in CA) and barren otherwise. (b) Depth zonation of New Zealand reef communities two years after establishment of the Leigh Marine reserve, reproduced from Leleu et al. 2012. Inset in shows the local kelp and barren patchiness in mid-depth zones, and "shallow zone" denotes intertidal and shallow sub-tidal areas dominated by wave-tolerant brown algal species other than Ecklonia. (d) Reef-scale patchiness of forest and barren community states at Santa Rosa Island, California in 2016 from satellite imagery (shaded areas) and 6 monitoring sites (arrows, with arrow color denoting site state).
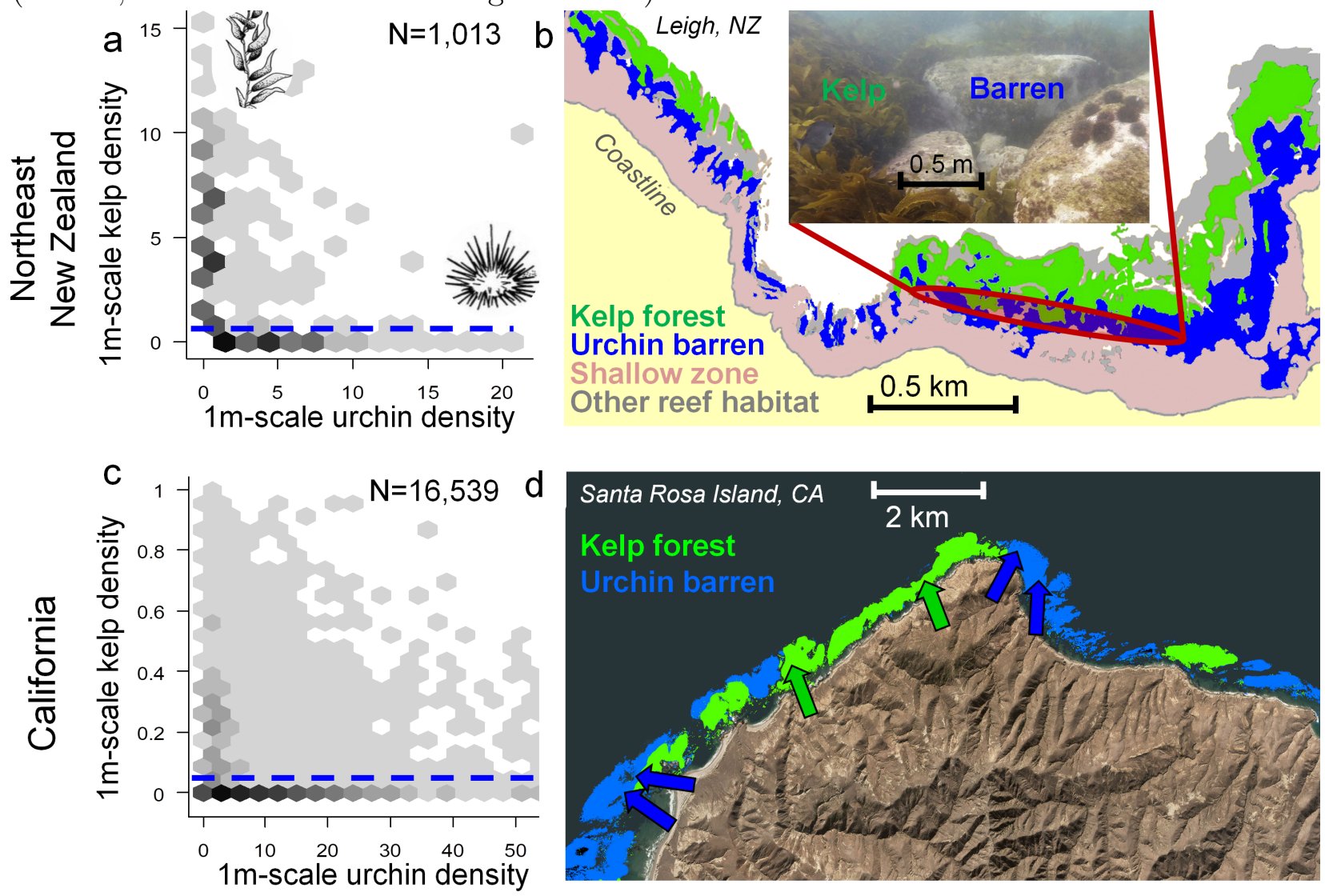
Figure 2: Model layout. (a) Local samples (red bars) on each reef span a depth gradient that influences wave intensity and light attenuation. Across reefs, forested and barren community types follow depth zonation in New Zealand but span entire reefs in California. (b) Dynamics of local kelp abundance $N_{q}$ depend on environmental factors (red boxes), stochasticity, and urchin behavior (blue box) that affect adult survival (red line) or recruitment (green lines). Circular endpoints on lines denote negative effects and flat endpoints denote positive effects; stochasticity in recruit survival $\Omega_{R}$ (lightning bolt and inset distribution) can have positive $\left(\Omega_{R}>1\right)$ or negative $\left(\Omega_{R}<1\right)$ effects depending on year and site. (c) Functional form of grazing with behavioral feedbacks absent (black) or present (blue), where urchins graze less at high kelp density $N_{x}$. (d) Reef-scale feedbacks where passive drift kelp subsidies at high kelp densities $N_{s}$ reduce urchin grazing across the reef (blue lines), as expected to be relevant in California. (e) Local-scale feedbacks where predators and physical abrasion in dense kelp stands deter grazing locally (blue lines), as expected to be relevant in New Zealand.

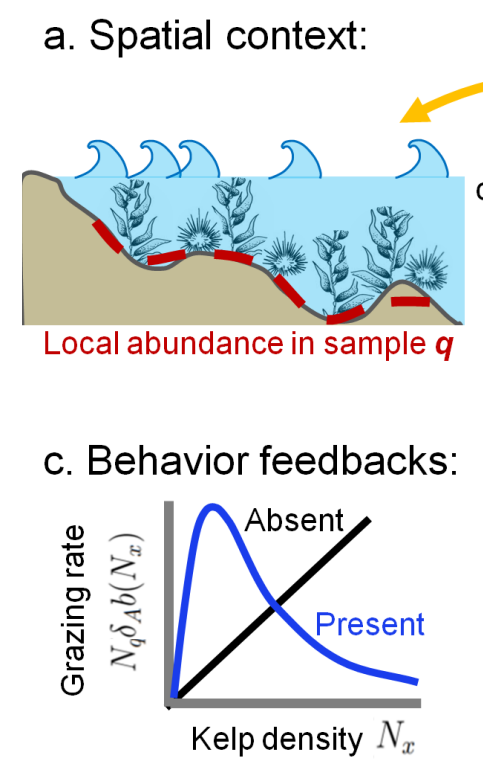

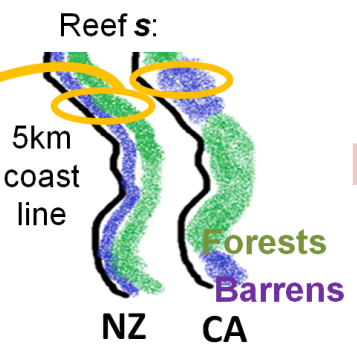

d. Reef-scale feedback:

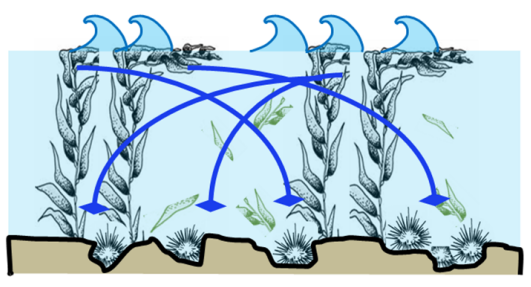

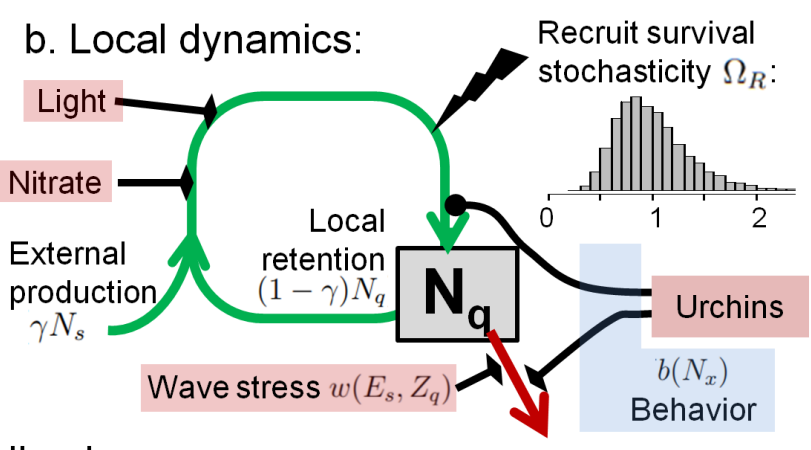

e. Local-scale feedback:

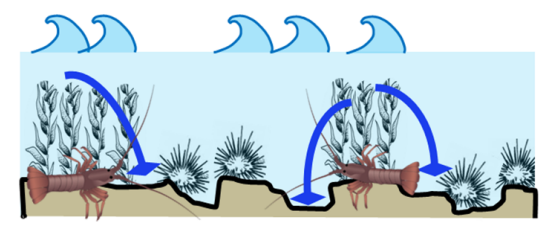


Figure 3: Behavioral feedbacks best explain observed patterns by predicting alternative stable kelp- and urchin-dominated states under moderate urchin densities. (a, b) Kelp density predicted by best-fitting models without behavior (red lines) and models with behavior (black lines) for simulations with initially high (solid lines) and initially low kelp densities (dashed lines; without behavior, identical to the solid line). Note the comparison of local kelp densities in (a) and reef-scale kelp densities in (b), reflecting the region-specific scale of feedbacks in our best-fitting models (Table 1). (c, d) Average difference in log likelihood between models with and without behavior, with greater differences denoting better fit.
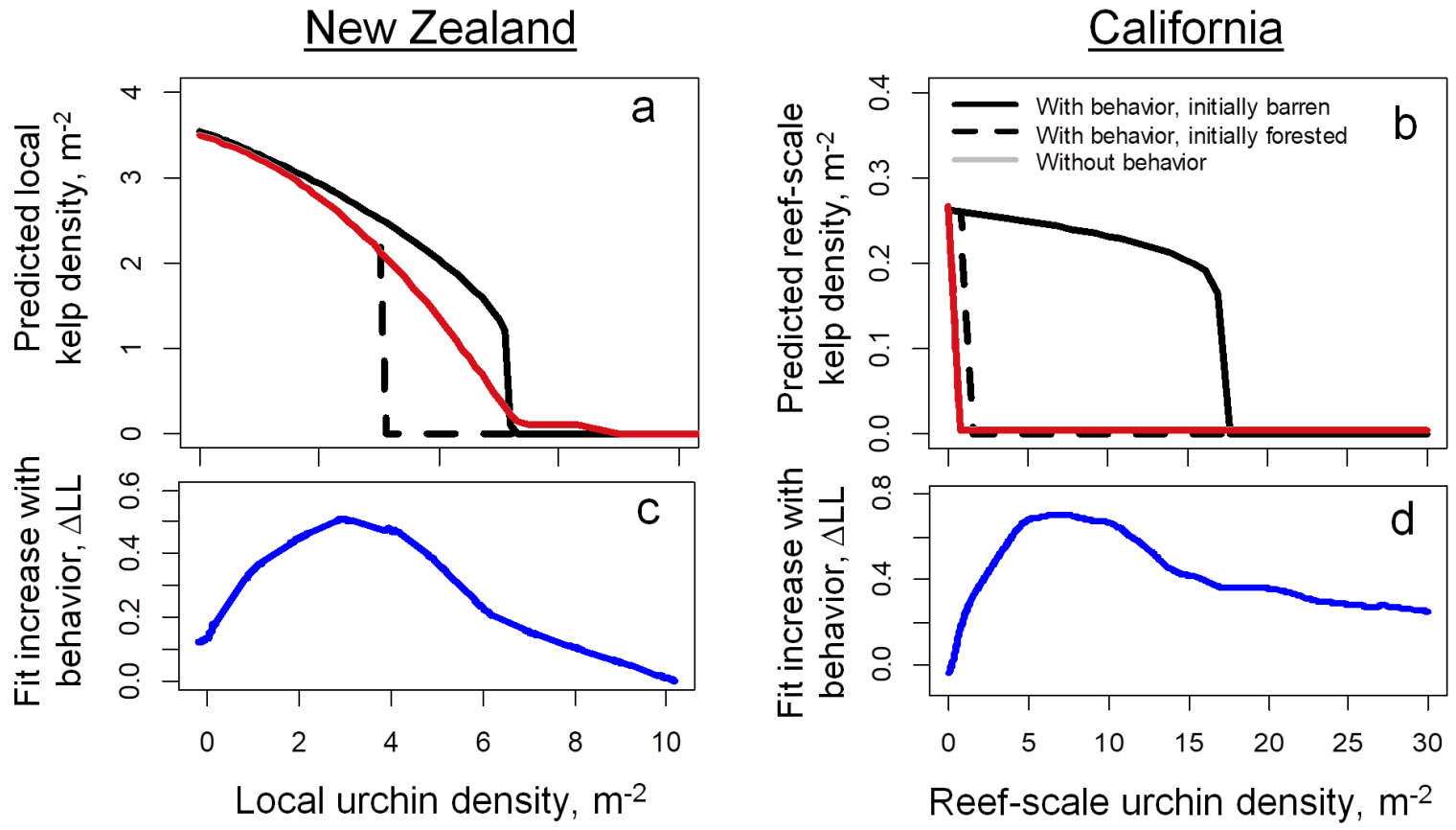
Figure 4: Regional differences in kelp distribution are best explained by a smaller scale of behavioral feedbacks and stronger wave stress gradients in New Zealand (a, b) compared to California (c, d). (a, c) Patterns in observed kelp density across depths on each reef (yaxes) and across reefs with increasing average urchin density. (b, d) Kelp densities predicted by best-fitting models in each region, with secondary y-axes denoting the best-fit, depthdependent estimates of mortality induced by wave stress. Gray dots in (a, c) denote the sample coverage across these conditions, with kelp density interpolated using 2-d splines. Hashed boxes in $(b, d)$ denote conditions for which best-fitting models predict alternative stable states with kelp present or absent.
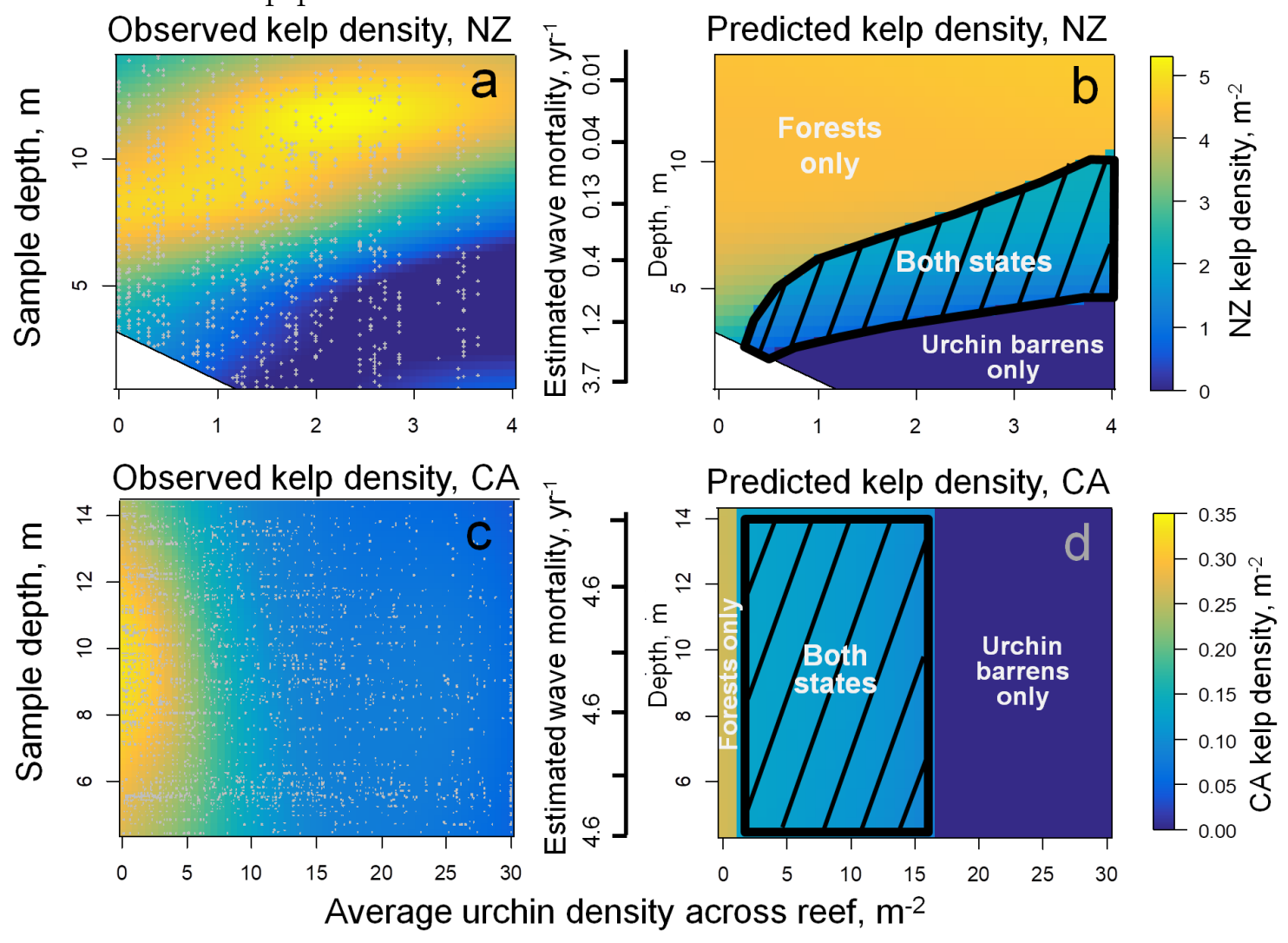
Figure 5: Best-fitting models with behavioral feedbacks predict alternative stable states that span a fraction of each reef in New Zealand (a) and entire reefs in California (b). (a, b) Frequency of kelp presence across reef predicted by best-fitting models without behavior (red lines) and models with behavior (black lines) for simulations with initially high (solid lines) and initially low kelp densities (dashed lines, identical to the solid line in the model without behavior). Blue dots show frequencies of kelp presence across all samples on each reef, with different dots representing different reefs and (in b) reefs in different years. (c,d) Sizes of barren and forested patches in data (yellow) and in best-fitting models without (red) and with (blue) behavior, with most patch sizes in California exceeding 100m due to limited spatial extent of sampling. $R_{\text {pres }}^{2}$ in $(\mathrm{c}, \mathrm{d})$ is the squared correlation between predicted and observed kelp presence (Table 1).
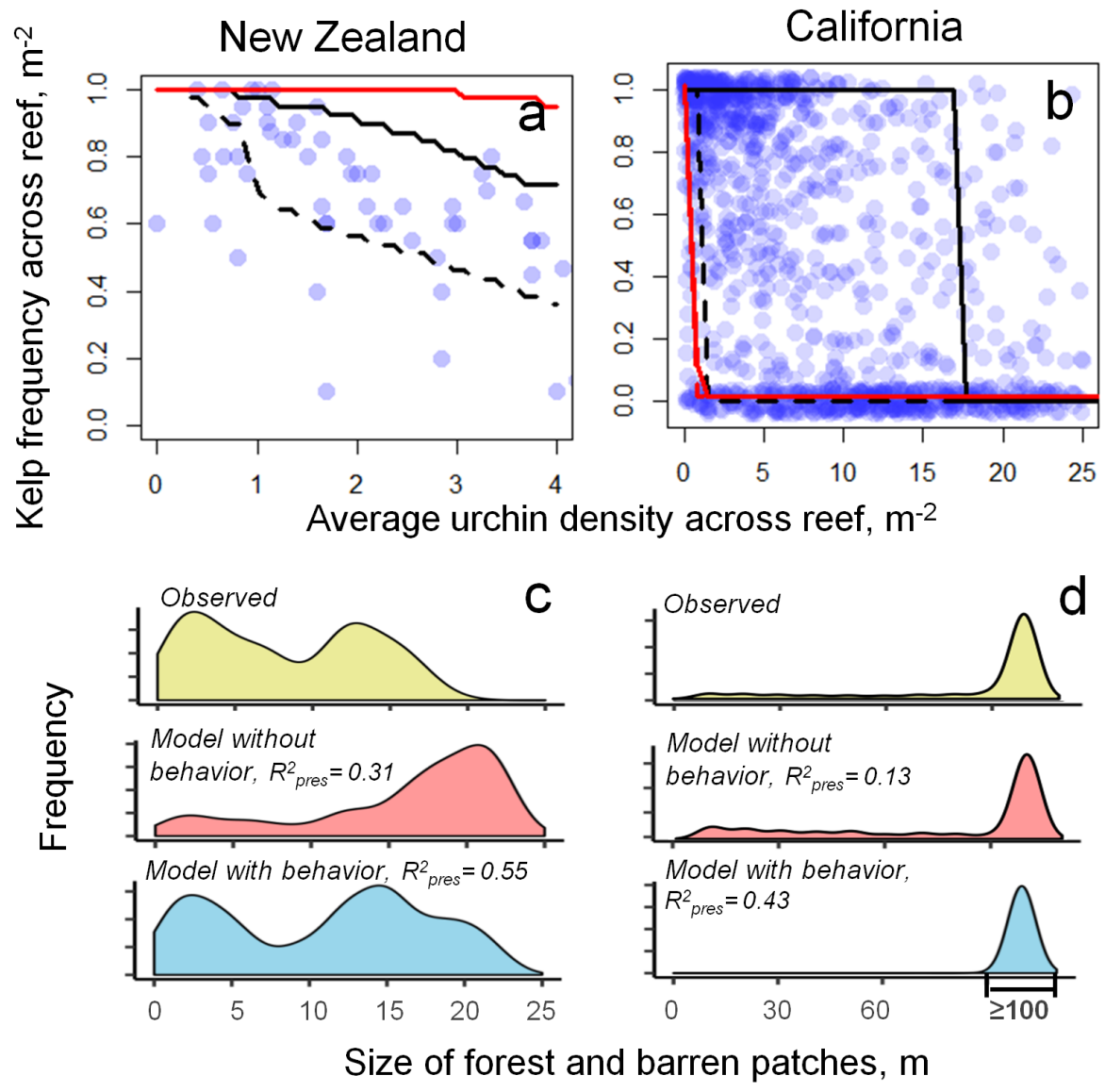
bioRxiv preprint doi: https://doi.org/10.1101/722215; this version posted August 24,2020 . The copyright holder for this preprint (which was not certified by peer review) is the author/funder, who has granted bioRxiv a license to display the preprint in perpetuity. It is made available under aCC-BY-NC-ND 4.0 International license.
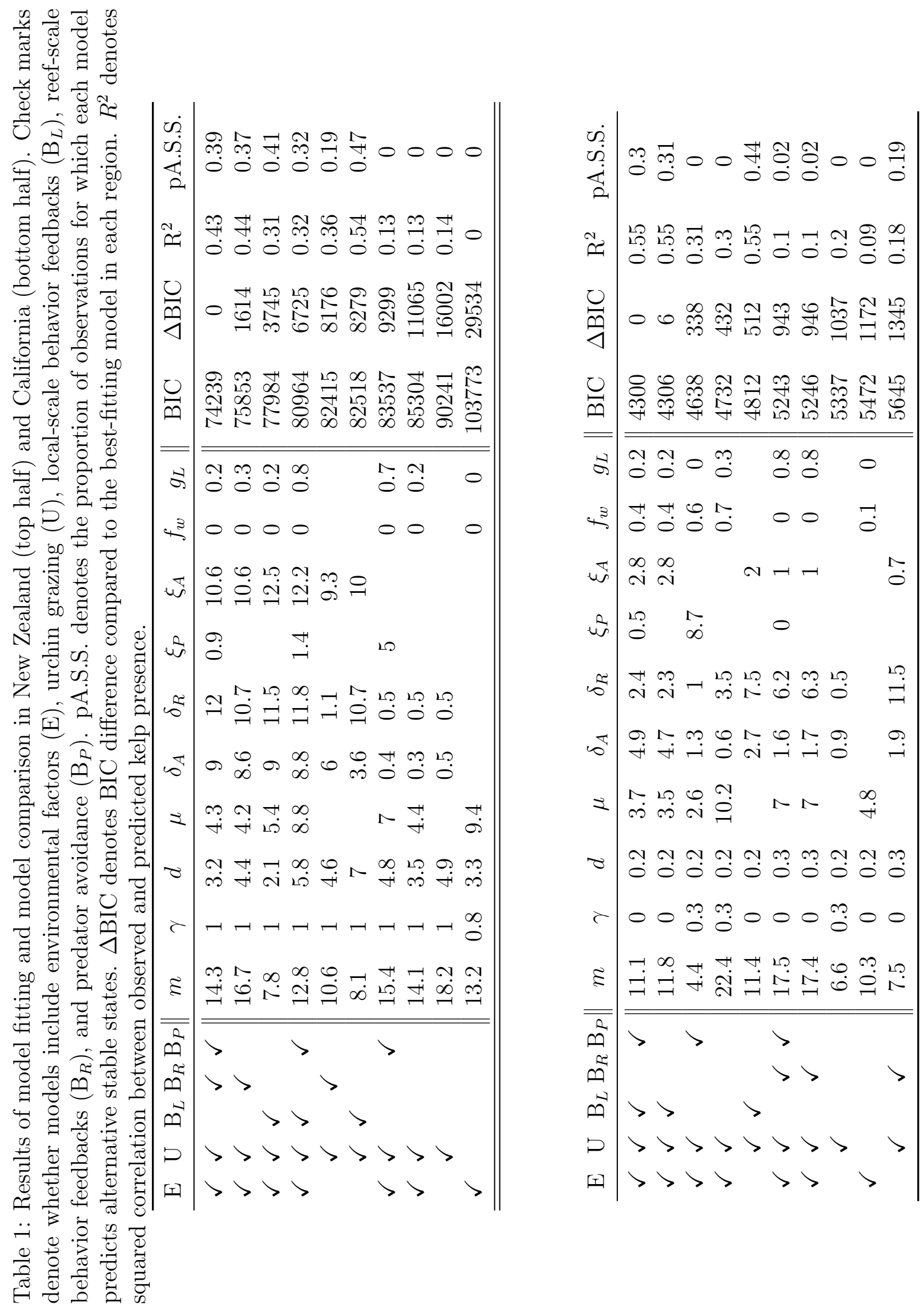


\section{References}

Anderson, E.K. \& North, W.J. (1966). In situ studies of spore production and dispersal in the giant kelp, macrocystis. In: Proceedings of the Fifth International Seaweed Symposium, Halifax, August 25-28, 1965. Elsevier.

Bate, A.M. \& Hilker, F.M. (2014). Disease in group-defending prey can benefit predators. Theor. Ecol., 7, 87-100.

Bekkby, T., Isachsen, P.E., Isæus, M. \& Bakkestuen, V. (2008). Gis modeling of wave exposure at the seabed: a depth-attenuated wave exposure model. Mar. Geod., 31, 117127.

Bell, T.W., Reed, D.C., Nelson, N.B. \& Siegel, D.A. (2018). Regional patterns of physiological condition determine giant kelp net primary production dynamics. Limnol. Oceanogr., $63,472-483$.

Bolker, B.M. (2008). Ecological models and data in R. Princeton University Press.

Caselle, J.E., Davis, K. \& Marks, L.M. (2018). Marine management affects the invasion success of a non-native species in a temperate reef system in california, usa. Ecol. Lett., $21,43-53$.

Cavanaugh, K.C., Kendall, B.E., Siegel, D.A., Reed, D.C., Alberto, F. \& Assis, J. (2013). Synchrony in dynamics of giant kelp forests is driven by both local recruitment and regional environmental controls. Ecology, 94, 499-509.

Cavanaugh, K.C., Siegel, D.A., Raimondi, P.T. \& Alberto, F. (2014). Patch definition in metapopulation analysis: a graph theory approach to solve the mega-patch problem. Ecology, 95, 316-328.

Cavanaugh, K.C., Siegel, D.A., Reed, D.C. \& Dennison, P.E. (2011). Environmental controls of giant-kelp biomass in the Santa Barbara Channel, California. Mar. Ecol. Prog. Ser., $429,1-17$.

Cowen, R.K. (1983). The effects of sheephead (Semicossyphus pulcher) predation on red sea urchin (Strongylocentrotus franciscanus) populations: an experimental analysis. Oecologia, 58, 249-255.

Dayton, P.K. (1971). Competition, Disturbance, and Community Organization - Provision and Subsequent Utilization of Space in a Rocky Intertidal Community. Ecol. Monogr., 41, $351-\&$.

Dayton, P.K. (1985a). Ecology of kelp communities. Annu. Rev. Ecol. Evol. Syst., 16, $215-245$.

Dayton, P.K. (1985b). The structure and regulation of some south american kelp communities. Ecol. Monogr., 55, 447-468. 
Downing, A.S., van Nes, E.H., Mooij, W.M. \& Scheffer, M. (2012). The Resilience and Resistance of an Ecosystem to a Collapse of Diversity. PLoS One, 7.

Ebeling, A.W., Laur, D.R. \& Rowley, R.J. (1985). Severe storm disturbances and reversal of community structure in a southern california kelp forest. Mar. Biol., 84, 287-294.

Filbee-Dexter, K. \& Scheibling, R.E. (2014). Sea urchin barrens as alternative stable states of collapsed kelp ecosystems. Mar. Ecol. Prog. Ser., 495, 1-25.

Fortin, D., Beyer, H.L., Boyce, M.S., Smith, D.W., Duchesne, T. \& Mao, J.S. (2005). Wolves influence elk movements: behavior shapes a trophic cascade in yellowstone national park. Ecology, 86, 1320-1330.

Gil, M.A., Baskett, M.L., Munch, S.B. \& Hein, A.M. (In review). Fast behavioral feedbacks make ecosystems sensitive to pace and not just magnitude of anthropogenic environmental change. Proceedings-of-the-National-Academy-of-Sciences-of-the-United-Statesof-America.

Gil, M.A. \& Hein, A.M. (2017). Social interactions among grazing reef fish drive material flux in a coral reef ecosystem. Proc. Natl. Acad. Sci. U. S. A., 114, 4703-4708.

Gil, M.A., Hein, A.M., Spiegel, O., Baskett, M.L. \& Sih, A. (2018). Social information links individual behavior to population and community dynamics. Trends Ecol. Evol., 33, $535-548$.

Grace, R.V. (1983). Zonation of sublittoral rocky bottom marine life and its changes from the outer to the inner hauraki gulf, northeastern new zealand. Tane, 29, 97-108.

Hamilton, S.L. \& Caselle, J.E. (2015). Exploitation and recovery of a sea urchin predator has implications for the resilience of southern California kelp forests. Proc. R. Soc. B-Biol. Sci., 282.

Harrold, C. \& Reed, D.C. (1985). Food availability, sea urchin grazing, and kelp forest community structure. Ecology, 66, 1160-1169.

Hiemstra, C.A., Liston, G.E. \& Reiners, W.A. (2006). Observing, modelling, and validating snow redistribution by wind in a Wyoming upper treeline landscape. Ecol. Model., 197, $35-51$.

Ives, A.R., Einarsson, Á., Jansen, V.A.A. \& Gardarsson, A. (2008). High-amplitude fluctuations and alternative dynamical states of midges in lake myvatn. Nature, 452, 84 .

Johnson, S.G. (2019). The nlopt nonlinear-optimization package. URL http://ab-initio. mit. edu/nlopt.

Karatayev, V.A. \& Baskett, M.L. (2020). At what spatial scales are alternative stable states relevant in highly interconnected ecosystems? Ecology.

Klausmeier, C.A. (1999). Regular and irregular patterns in semiarid vegetation. Science, $284,1826-1828$. 
Koen-Alonso, M. (2007). A process-oriented approach to the multispecies functional response. In: From energetics to ecosystems: the dynamics and structure of ecological systems. Springer, pp. 1-36.

Konar, B. (2000). Seasonal inhibitory effects of marine plants on sea urchins: structuring communities the algal way. Oecologia, 125, 208-217.

Kushner, D.J., Rassweiler, A., McLaughlin, J.P. \& Lafferty, K.D. (2013). A multi-decade time series of kelp forest community structure at the california channel islands: Ecological archives e094-245. Ecology, 94, 2655.

Lafferty, K.D. (2004). Fishing for lobsters indirectly increases epidemics in sea urchins. Ecol. Appl., 14, 1566-1573.

Laundré, J.W., Hernández, L. \& Altendorf, K.B. (2001). Wolves, elk, and bison: reestablishing the" landscape of fear" in yellowstone national park, usa. Can. J. Zool., 79, 1401-1409.

Lauzon-Guay, J.S. \& Scheibling, R.E. (2007). Behaviour of sea urchin strongylocentrotus droebachiensis grazing fronts: food-mediated aggregation and density-dependent facilitation. Mar. Ecol. Prog. Ser., 329, 191-204.

Leleu, K., Remy-Zephir, B., Grace, R. \& Costello, M.J. (2012). Mapping habitats in a marine reserve showed how a 30-year trophic cascade altered ecosystem structure. Biol. Cons., 155, 193-201.

Ling, S.D., Scheibling, R.E., Rassweiler, A., Johnson, C.R., Shears, N., Connell, S.D. et al. (2015). Global regime shift dynamics of catastrophic sea urchin overgrazing. Philos. Trans. R. Soc. B-Biol. Sci., 370.

McPeek, M.A. \& Peckarsky, B.L. (1998). Life histories and the strengths of species interactions: Combining mortality, growth, and fecundity effects. Ecology, 79, 867-879.

Moreno, C.A. \& Sutherland, J.P. (1982). Physical and biological processes in a macrocystis pyrifera community near valdivia, chile. Oecologia, 55, 1-6.

Mumby, P.J., Hastings, A. \& Edwards, H.J. (2007). Thresholds and the resilience of caribbean coral reefs. Nature, 450, 98-101.

Mumby, P.J., Steneck, R.S. \& Hastings, A. (2013). Evidence for and against the existence of alternate attractors on coral reefs. Oikos, 122, 481-491.

Noy-Meir, I. (1975). Stability of grazing systems: an application of predator-prey graphs. J. Ecol., 459-481.

Okamoto, D.K. (2014). The role of fluctuating food supply on recruitment, survival and population dynamics in the sea. University of California, Santa Barbara.

Parsons, D.M., Shears, N.T., Babcock, R.C. \& Haggitt, T.R. (2004). Fine-scale habitat change in a marine reserve, mapped using radio-acoustically positioned video transects. Mar. Freshw. Res., 55, 257-265. 
Peckarsky, B.L., Abrams, P.A., Bolnick, D.I., Dill, L.M., Grabowski, J.H., Luttbeg, B., Orrock, J.L., Peacor, S.D., Preisser, E.L., Schmitz, O.J. \& Trussell, G.C. (2008). Revisiting the classics: Considering nonconsumptive effects in textbook examples of predator-prey interactions. Ecology, 89, 2416-2425.

Petraitis, P. (2013). Multiple stable states in natural ecosystems. In: Multiple stable states in natural ecosystems. Oxford University Press, New York, NY, pp. 1-188.

Petraitis, P.S. \& Dudgeon, S.R. (2004). Detection of alternative stable states in marine communities. J. Exp. Mar. Biol. Ecol., 300, 343-371.

R Core Team (2017). R: A language and environment for statistical computing.

Reed, D.C., Amsler, C.D. \& Ebeling, A.W. (1992). Dispersal in kelps: factors affecting spore swimming and competency. Ecology, 73, 1577-1585.

Rietkerk, M. \& Van de Koppel, J. (2008). Regular pattern formation in real ecosystems. Trends Ecol. Evol., 23, 169-175.

Scheffer, M., van Nes, E.H., Holmgren, M. \& Hughes, T. (2008). Pulse-driven loss of topdown control: The critical-rate hypothesis. Ecosystems, 11, 226-237.

Schneider, F.D. \& Kefi, S. (2016). Spatially heterogeneous pressure raises risk of catastrophic shifts. Theor. Ecol., 9, 207-217.

Shears, N.T. \& Babcock, R.C. (2004). Community composition and structure of shallow subtidal reefs in northeastern New Zealand. Department of Conservation Wellington.

Shears, N.T., Babcock, R.C. \& Salomon, A.K. (2008). Context-Dependent Effects of Fishing: Variation in Trophic Cascades Across Environmental Gradients. Ecol. Appl., 18, 18601873.

Shears, N.T., Kushner, D.J., Katz, S.L. \& Gaines, S.D. (2012). Reconciling conflict between the direct and indirect effects of marine reserve protection. Environ. Conserv., 39, 225-236.

Silliman, B.R., McCoy, M.W., Angelini, C., Holt, R.D., Griffin, J.N. \& van de Koppel, J. (2013). Consumer fronts, global change, and runaway collapse in ecosystems. Annu. Rev. Ecol. Evol. Syst., 44, 503-538.

Sinclair, A.R.E. (1977). The african buffalo; a study of resource limitation of populations.

Topping, D.T., Lowe, C.G. \& Caselle, J.E. (2005). Home range and habitat utilization of adult california sheephead, semicossyphus pulcher (Labridae), in a temperate no-take marine reserve. Mar. Biol., 147, 301-311.

van de Leemput, I.A., Hughes, T.P., van Nes, E.H. \& Scheffer, M. (2016). Multiple feedbacks and the prevalence of alternate stable states on coral reefs. Coral Reefs, 35, 857-865. 
van den Berg, M.S., H, C., L, M.M., M, S. \& J, S. (1998). Clear water associated with a dense Chara vegetation in the shallow and turbid Lake Veluwemeer, the Netherlands. In: Structuring role of submerged macrophytes in lakes (ed. Jeppesen E and Sondergaard M and Sondergaard M and Kristoffersen K). Springer-Verlag, New York, NY, pp. 339-352.

van Nes, E.H. \& Scheffer, M. (2005). Implications of spatial heterogeneity for catastrophic regime shifts in ecosystems. Ecology, 86, 1797-1807.

Vásquez, J.A. \& Buschmann, A.H. (1997). Herbivore-kelp interactions in chilean subtidal communities: a review. Rev. Chil. Hist. Nat., 70, 41-52.

Vásquez, J.A., Castilla, J.C. \& Santelices, B. (1984). Distributional patterns and diets of four species of sea urchins in giant kelp forest(macrocystis pyrifera) of puerto toro, navarino island, chile. Mar. Ecol. Prog. Ser., 19, 55-63.

Whittaker, R.H. (1960). Vegetation of the siskiyou mountains, oregon and california. Ecol. Monogr., 30, 279-338. 


\section{Appendix A: Dataset and covariates}

We use survey data collected in New Zealand during the 1999-2000 winter growing season (Shears \& Babcock 2004). For California, we use data collected in both the National Park Service Kelp Forest Monitoring survey (5644 samples, 1996-2017, 'KFM' hereafter; Kushner et al. 2013), which samples a wide range of years and collects many samples at each location, and the Partnership for the Interdisciplinary Studies of Coastal Oceans survey (9311 samples, 1999-2017, 'PISCO' hereafter; Casselle et al. 2015), which samples a greater number of reefs and a gradient of depths at each reef.

Adult kelp densities in New Zealand were sampled in $1 \mathrm{~m}^{2}$ quadrats stratified by water depth. In California, kelp counts were sampled in either $20 \mathrm{~m}^{2}$ areas (PISCO swath surveys) or in $5 \mathrm{~m}^{2}$ quadrats (KFM); for KFM data we pooled data from adjacent quadrats to yeild kelp counts at the $20 \mathrm{~m}^{2}$ scale. The difference in sampling scale across regions reflects the 20-fold lower densities of Macrocystis pyrifera in CA compared to Ecklonia radiata in NZ (Fig. 1). Analogously to New Zealand data, KFM surveys counted the abundance of $>1 \mathrm{~m}$ tall adult $M$. pyrifera (plants with haptera at or above the primary dichotomy, Kushner et al. 2013). Based on KFM 'Natural Habitat Size Frequency' data for each reef and year, we found that the frequency of adults among $>1 \mathrm{~m}$ tall $M$. pyrifera was best approximated by the frequency of $>1 \mathrm{~m}$ tall plants with $>5$ stipes $1 \mathrm{~m}$ above the bottom $\left(R^{2}=0.57\right)$. Using this conversion, we determined the abundance of adult $M$. pyrifera in PISCO surveys, which quantified the number of stipes on each $>1 \mathrm{~m}$ tall $M$. pyrifera but did not classify plant life stage.

Urchin densities were quantified in stratified $1 \mathrm{~m}^{2}$ quadrats (NZ), 20m² areas (PISCO swath surveys) or in $1 \mathrm{~m}^{2}$ quadrats (KFM). In all studies, density estimates represent urchins of sufficient size to consume kelp ( $\geq 25 \mathrm{~mm}$ test diameter). As KFM surveys counted urchins of all sizes, we multiplied densities in KFM samples by the (species-specific) fraction of individuals $\geq 25 \mathrm{~mm}$ in size-frequency data on $\geq 30$ randomly selected individuals at each reef ('Natural Habitat Size Frequencies', Kushner et al. 2013). Additionally, as with kelp counts, for KFM data we averaged urchin densities among adjacent quadrats to estimate density (ind $\mathrm{m}^{-2}$ ) at the $20 \mathrm{~m}^{2}$ scale. Finally, we pooled urchin density across purple (Strongylocentrotus purpuratus) and red (Mesocentrotus franciscanus) sea urchins in California samples.

In New Zealand, we omitted samples dominated by wave-tolerant brown algae which were not included in our model but can displace Ecklonia and sparse urchins from shallow areas. To systematically exclude these samples, we first identified samples dominated by brown algae ( $>20$ individuals, $<2$ urchins, and $<5$ Ecklonia, but results were not sensitive to these thresholds). To identify the depth extent of brown algal dominance, on each reef we calculated the 80th percentile of depths for samples dominated by brown algae. To account for the possibility that intense urchin grazing can exclude brown algae even from shallow areas, we fit a generalized additive model relating the depth extent of brown algal dominance to site-level urchin density using splines. This model predicted that brown algae are restricted to shallower depths at sites with more urchins. We then excluded the 228 samples where our model predicted brown algal dominance from our analysis (Fig. S1). 
Figure S1: Depth extent of dominance by wave-tolerant brown algae (y-axis) on reefs in New Zealand (points) across sites with increasing urchin density (x-axis). Fitted curve represents a best-fit spline model, with dotted lines denoting model standard error. Shaded area denotes depths and site-level urchin densities at which samples were excluded from analysis.

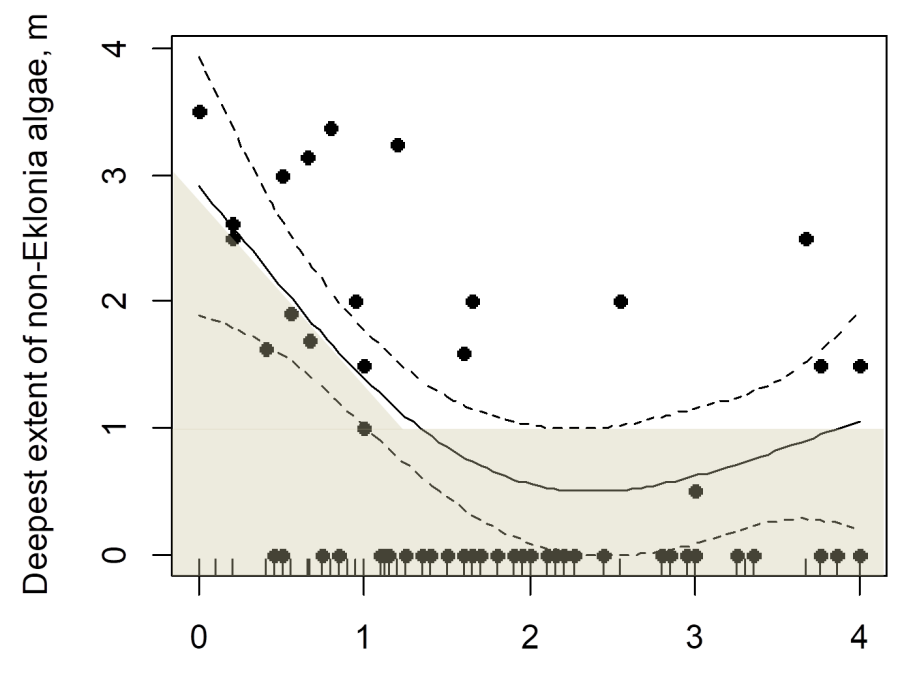

Average urchin density across reef, ind $\mathrm{m}^{\wedge}-2$

For New Zealand, we determine predator density as the sum of snapper (Pagrus auratus) and lobster (Jasus edwardsii) densities estimated at the approximate time of kelp and urchin density surveys (Kelly et al. 2000; Willis et al. 2003; Shears et al. 2008). At KFM reefs in California, we determined predator density as the sum of sheephead (Semicossyphus pulcher) densities recored in Fish Visual Transects and sunflower seastar (Pycnopodia helianthoides) and spiny lobster (Panulirus interruptus) measured in $1260 \mathrm{~m}^{2}$ Band Transects (Kushner et al. 2013). At PISCO reefs in California, predator density is the sum of sheephead densities in fish visual surveys covering $120 \mathrm{~m}^{2}\left(480 \mathrm{~m}^{3}\right.$ volume $)$ and lobster and seastar densities in swath samples spanning $260 \mathrm{~m}^{2}$ areas (mean swath area across reefs and years). Given greater sampling uncertainty in density (i.e., greater coefficient of variance) and the larger time scale of population dynamics of predators compared with kelp and urchins, we smooth reef-scale predator densities in California using a 3-year running average across sampling years.

We quantify the fraction of surface light reaching the bottom in each sample $q$ at depth $Z_{q}$ using reef-specific secchi depth measurements $D_{s}$ as $\exp \left(-1.7 D_{s}^{-1} Z_{q}\right)$. In New Zealand, wave stress $E_{s}$ predominantly arises from waves generated by wind; we therefore use an index of potential wind fetch (Thomas 1986) as the proxy for wave stress. In California, kelp biomass can greatly depend on maximum wave height (Bell et al. 2015), but this environmental driver depends on both wind, coastal currents, and local reef topography. As a proxy for $E_{s}$ we therefore use estimates of reef- and year-specific maximum wave height from (Lafferty et al. 2019), which calibrates maximum wave height estimates from regional oceanographic models using near-bottom sensors at each survey reef.

Finally, in California, large temperature variation driven by upwelling can cause nitrate depletion at high water temperatures (in New Zealand, lower peak temperatures rarely de- 
plete nitrate). Nitrate limitation can reduce growth and total kelp biomass (not modeled here) as well as kelp fecundity (Bell et al. 2018). We include reef- and year-specific nitrate availability $G_{s}$ estimated in Bell et al. 2018 from ocean temperature (projected locally using calibrated ocean circulation models) and observed relations of nitrate depletion with increasing temperatures. We modeled a decline in fecundity at low $G_{s}$ using a function that saturates to 1 at high nitrate levels given saturation constant $v$, and change eqn. 1 to

$$
r\left(N_{q}, N_{s}\right)=\frac{m G_{s}}{1+v G_{s}}\left(\gamma N_{s}+(1-\gamma) N_{q}\right)
$$

Adding nitrate to our models including environment, urchin grazing, and urchin behavior did not improve the fit of our best model based on BIC.

Table S1: Model parameters fitted to data in each region and model covariates. Covariates are given by environmental data and parameters are estimated in model fitting. Covariates without units are proportions of region-specific maximum values.

\begin{tabular}{ccl}
\hline Parameter & Units & Description \\
\hline$m$ & $\mathrm{yr}^{-1}$ & Adult kelp fecundity \\
$\sigma_{R}$ & & Standard deviation in recruit survival, fixed $\sigma_{R}=0.35$ \\
$\gamma$ & & Fraction of kelp spores dispersing across reef \\
$g_{L}$ & & Contribution of measured light availability to recruitment \\
$d$ & $\mathrm{~N}^{-1}$ & Kelp competition for light inhibiting recruitment \\
$\mu$ & $\mathrm{yr}^{-1}$ & Kelp mortality from wave stress \\
$f_{w}$ & $\mathrm{~m}^{-1}$ & Per-meter wave energy dissipation \\
$\delta_{A}$ & $\mathrm{U}^{-1} \mathrm{yr}^{-1}$ & Max grazing intensity on adult kelp \\
$\delta_{R}$ & $\mathrm{U}^{-1}$ & Max grazing intensity on kelp recruits \\
$\xi_{A}$ & $\mathrm{~N}^{-1}$ & Grazing inhibition by adult kelp \\
$\xi_{P}$ & $\mathrm{P}^{-1}$ & Grazing inhibition by predators \\
\hline Covariate & $\mathrm{Units}$ & Description \\
\hline$Z_{q}$ & $\mathrm{~m}$ & Sample depth \\
$L_{q}$ & & Local light availability at bottom \\
$U_{q}$ & ind m & Local > 25mm urchin density \\
$E_{s}$ & & Reef-scale wave stress \\
$G_{s}$ & & Reef-scale nitrate availability (CA only) \\
$P_{s}$ & ind m & Reef-scale urchin predator density \\
\hline
\end{tabular}

\section{Literature cited}

Bell, T.W., Cavanaugh, K.C., Reed, D.C. \& Siegel, D.A. (2015). Geographical variability in the controls of giant kelp biomass dynamics. J. Biogeogr., 42, 2010-2021.

Caselle, J.E., Rassweiler, A., Hamilton, S.L. \& Warner, R.R. (2015). Recovery trajectories of kelp forest animals are rapid yet spatially variable across a network of temperate marine protected areas. Sci. Reports, 5, 14102. 
Kelly, S., Scott, D., MacDiarmid, A.B. \& Babcock, R.C. (2000). Spiny lobster, Jasus edwardsii, recovery in New Zealand marine reserves. Biol. Cons., 92, 359-369.

Lafferty, K.D., Rassweiler, A., Gotschalk, C.C., Morton, D.N., Bell, T.W., Henderikx, F., Kushner, D.J., Sprague, J., Johnson, C. \& Washburn, L. (2019). The response of kelp forest organisms to spatial and temporal variation in wave energy in the California Channel Islands. US Department of the Interior, Bureau of Ocean Energy Management. OCS Study BOEM, 64, 38 .

Willis, T.J., Millar, R.B. \& Babcock, R.C. (2003). Protection of exploited fish in temperate regions: high density and biomass of snapper Pagrus auratus (Sparidae) in northern New Zealand marine reserves. J. Appl. Ecol., 40, 214-227.

\section{Appendix B: Convergence deviations of fitted models}

Here we determine the deviation of kelp abundance from model steady states after simulating population dynamics for a single year. We quantify these deviations for each model under the best-fit parameter set and across all initial conditions and realizations of juvenile survival stochasticity $\Omega_{R}$ (Table $\mathrm{S} 2$ ). In our best-supported models, kelp density approaches close to steady state within a single year in nearly all samples (kelp density difference of 99\% in NZ, 93\% in CA in samples with kelp; Fig. S2) and in most samples approaches close to steady state during the growing season (i.e., in $\leq 5$ months, $98 \%$ in NZ, $83 \%$ in CA). All other fitted models analogously approach close to steady state within a year (Table S2). Greater deviations from equilibrium kelp abundance in California compared to New Zealand arise because the best-fit models in California assume strong coupling of kelp population dynamics across each reef by spore dispersal. This coupling among locations by recruitment leads to longer transient dynamics. 
Figure S2: Within-year dynamics of kelp density (averaged over the entire reef) projected in best-supported models in California (a) and New Zealand (b). Trajectories in each system show dynamics from high (black lines) and low (red lines) initial kelp density for 3 (randomly selected) reefs with no alternative stable states predicted (solid lines), which converge on the same density, and 3 reefs with alternative stable states predicted (dashed lines).
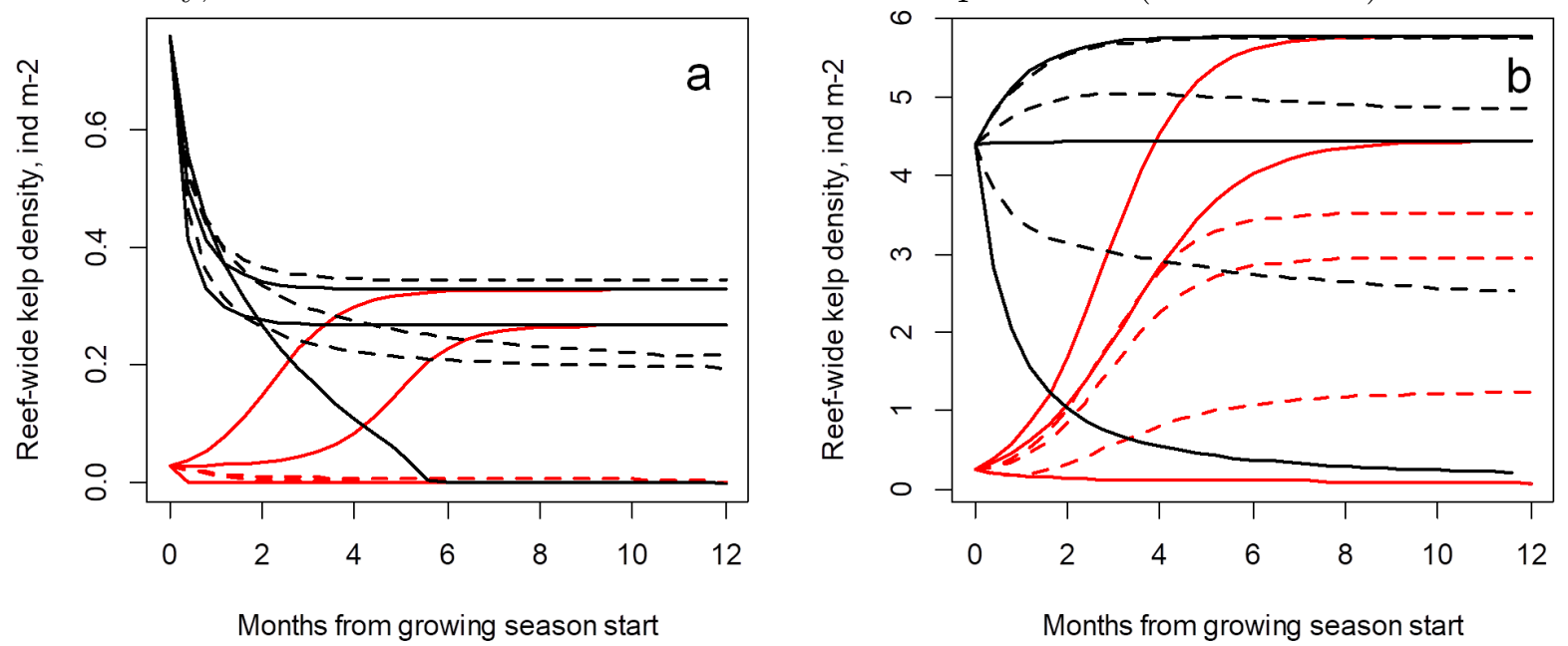

Table S2: Mean and median deviation of kelp abundance from model steady states after simulating population dynamics for a single year, across all models fitted for New Zealand (top rows) and California (bottom rows). Relative ("Rel." in table) deviations denote absolute deviations scaled by median kelp abundance in each region ( 4 in NZ, 0.2 in CA). Model nomenclature follows Table 1.

\begin{tabular}{ccccc||cccc}
\hline $\mathrm{E}$ & $\mathrm{U}$ & $\mathrm{B}_{L}$ & $\mathrm{~B}_{R}$ & $\mathrm{~B}_{P}$ & Mean Deviation & Mean Rel. Deviation & Median Rel. Deviation \\
$\checkmark$ & $\checkmark$ & $\checkmark$ & & $\checkmark$ & 0.03 & 0.01 & 0 \\
$\checkmark$ & $\checkmark$ & & & $\checkmark$ & 0.1 & 0.03 & 0 \\
$\checkmark$ & $\checkmark$ & & & & 0.05 & 0.01 & 0 \\
$\checkmark$ & & & & & 0.01 & 0 & 0 \\
& $\checkmark$ & $\checkmark$ & & & 0.14 & 0.03 & 0 \\
& $\checkmark$ & & & & 0.11 & 0.03 & 0 \\
& $\checkmark$ & & $\checkmark$ & & 0.13 & 0.03 & 0.01 \\
\hline \hline \multirow{2}{*}{$\checkmark$} & $\checkmark$ & & $\checkmark$ & $\checkmark$ & 0.03 & 0.13 & 0.01 \\
$\checkmark$ & $\checkmark$ & $\checkmark$ & & $\checkmark$ & 0.03 & 0.14 & 0 \\
& $\checkmark$ & $\checkmark$ & & & 0.02 & 0.08 & 0.06 \\
& $\checkmark$ & & $\checkmark$ & & 0.02 & 0.11 & 0 \\
& $\checkmark$ & & & $\checkmark$ & 0.04 & 0.18 & 0 \\
& $\checkmark$ & & & 0 & 0.02 & 0 \\
\hline
\end{tabular}




\section{Appendix C: Temporally explicit model fits}

Here we verify that the model ranking results of our main analysis, which assumes kelp densities each year reach steady state, are preserved in models with temporally explicit fits. We use a subset of California data collected at KFM long-term monitoring sites, which represent the longest time series in our data (11-22 years at each of 33 sites, 5564 total samples) collected on fixed transects (i.e., identical reef areas sampled each year). Using each model we predict the distribution of kelp across a reef $s$ in year $t, \vec{N}_{t, j}$, based on that year's environmental conditions and using kelp distribution $n$ years ago $\vec{N}_{t-n, j}$ as the initial condition in the ODE. For $n>1$, we simulate the ODE using $\vec{N}_{t-n, j}$ as the initial condition and environmental conditions in each year $t-n+1$ to $t$, with each realization of recruitment conditions $\Sigma_{R}$ maintained throughout the $n$-year period.

We account for two system features that can affect the results of temporally explicit model fits. First, model ranking might poorly distinguish competing models when modeled processes account for a limited portion of population dynamics (e.g., $R^{2}=0.43$ for kelp presence in CA, Table 1) and data spans a limited range of environments and state space (i.e., 33 sites in temporally explicit fits versus 129 in our main CA analysis). We partially account for this by dividing kelp densities observed at each site $s$ by the kelp density found at site $s$ in samples with kelp, averaged over all years. Second, one-step-ahead fits might poorly estimate parameters due to temporal autocorrelation in kelp, urchins, and environmental conditions that makes $\vec{N}_{t, j}$ correspond more strongly to initial conditions $\vec{N}_{t-1, j}$ than to modeled processes. Given that autocorrelation reaches zero within 5 years for all observed variables, we additionally fit our best-supported model using 5-step-ahead model fits.

Model ranking in one-step-ahead fits is broadly consistent with our results for spatially implicit fits, with the best-fitting models including environment and reef-scale kelp-density behavior feedbacks (Table S3). As expected, one-step-ahead under-predicted urchin grazing rate $\delta_{A}$ compared to temporally implicit and 5-step-ahead model fits. Smaller differences in other parameter estimates (5-step-ahead fits) and the lack of support for predator avoidance in one-step-ahead fits compared to our main analysis might arise because temporally explicit fits exclude the majority of sites (75\%, see above) in our main analysis. However, we point out that the range kelp population growth estimates in all temporally explicit fits $(8.8 \leq m \leq$ $19.1)$ is in line with estimates of $m$ in our main analysis, supporting our central assumption that kelp density typically reaches steady state within a year. 
Table S3: Temporally explicit, one-step-ahead model fits (top rows) and five-steps-ahead (bottom row). Following Table 1, check marks denote whether models include environmental factors $(\mathrm{E})$, urchin grazing $(\mathrm{U})$, local-scale behavior feedbacks $\left(\mathrm{B}_{L}\right)$, reef-scale behavior feedbacks $\left(\mathrm{B}_{R}\right)$, and predator avoidance $\left(\mathrm{B}_{P}\right)$. $\Delta \mathrm{BIC}$ denotes $\mathrm{BIC}$ difference compared to the best-fitting model.

\begin{tabular}{|c|c|c|c|c|c|c|c|c|c|c|c|c|c|c|}
\hline $\mathrm{E}$ & $\mathrm{U}$ & $\mathrm{B}_{L} \mathrm{~B}_{R} \mathrm{~B}_{P}$ & $m$ & $\gamma$ & $d$ & $\mu$ & $\delta_{A}$ & $\delta_{R}$ & $\xi_{P}$ & $\xi_{A}$ & $f_{w}$ & $g_{L}$ & $\mathrm{BIC}$ & $\triangle \mathrm{BIC}$ \\
\hline$\checkmark$ & $\checkmark$ & $\checkmark$ & 9.5 & 0 & 3 & 8.1 & 0.5 & 12 & & 14.2 & 0 & 0.9 & 16316 & 0 \\
\hline$\checkmark$ & $\checkmark$ & $\checkmark \checkmark$ & 9.4 & 0 & 3 & 8.2 & 0.6 & 9.1 & 1.3 & 14.6 & 0 & 0.9 & 16328 & 12 \\
\hline$\checkmark$ & $\checkmark$ & $\checkmark$ & 17.8 & 0.8 & 3.6 & 11.4 & 2.9 & 9.2 & 0 & 13.6 & 0 & 0.9 & 17016 & 700 \\
\hline$\checkmark$ & $\checkmark$ & $\checkmark$ & 12.9 & 1 & 3 & 7.7 & 0.3 & 0.5 & 1.5 & & 0 & 1 & 17040 & 724 \\
\hline$\checkmark$ & $\checkmark$ & $\checkmark$ & 18.2 & 0.8 & 3.8 & 10.7 & 1.9 & 11 & & 12.6 & 0 & 0.9 & 17119 & 803 \\
\hline$\checkmark$ & $\checkmark$ & & 14.4 & 1 & 3 & 6.9 & 0.3 & 0.5 & & & 0 & 0.8 & 17528 & 1212 \\
\hline$\checkmark$ & & & 8.8 & 0 & 3 & 2.5 & & & & & 0 & 0 & 17664 & 1348 \\
\hline & $\checkmark$ & $\checkmark$ & 9.4 & 0 & 3.6 & & 0.7 & 1.9 & & 28.5 & & & 17946 & 1630 \\
\hline & $\checkmark$ & & 14.3 & 1 & 3.3 & & 0.3 & 0.5 & & & & & 19452 & 3136 \\
\hline & $\checkmark$ & $\checkmark$ & 19.1 & 0.9 & 4.2 & & 5.1 & 2.5 & & 14.6 & & & 20145 & 3829 \\
\hline$\checkmark$ & $\checkmark$ & $\checkmark \checkmark$ & 12.7 & 0.1 & 3 & 11.4 & 3.7 & 12 & 0.7 & 11.9 & 0 & 0.8 & 14315 & \\
\hline
\end{tabular}

\section{Appendix D: Behavioral declines in urchin grazing due to predators}

Predators could affect grazing through both direct effects on urchin density (numerical effect) and indirect effects through changes in urchin grazing behavior (grazing rate effect); our model in the main text focuses on the latter. Examining the potential magnitude of numerical predator effects on urchins, we found that predator densities explain only a fraction of among-reef variation in urchin densities (averaged over all quadrats on each reef and sampling year, $\mathrm{R}^{2}=0.22, \mathrm{p}<<0.001, \mathrm{n}=1267$, Fig. D1a). Remarkably, the decline in urchin

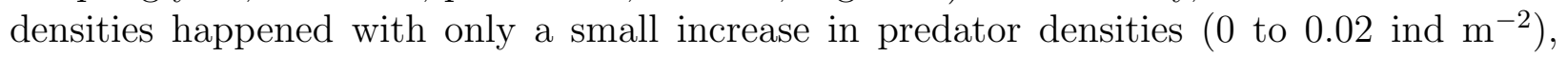
while further increases in predator density (0.02 to 0.15 ind $\mathrm{m}^{-2}$ ) had no effect on urchin density. Declines in urchin density over low predator densities only might also be explained by a strong urchin behavioral response where urchins are cryptic and harder to detect (i.e., quadrat samples under-estimating true densities) at sites where predators are present. To verify our density analysis, we examined whether predation reduced average size of urchins (test diameter of urchins $<70 \mathrm{~mm}$ ) found in quadrats along transects compared to urchins found in cages that largely exclude urchin predators ('Artificial Recruitment Modules', 5-15 permanent 5x12 cm mesh cages at each of 12 KFM monitoring sites). Overall, predator density poorly explained the difference in urchin size between quadrats and exclosures $\left(\mathrm{R}^{2}=0.12\right.$, $\mathrm{p}=0.0005, \mathrm{n}=211$, Fig. D1b), and urchins in exclosures did not have larger sizes at sites with high predator densities.

In New Zealand, large within-season changes in urchin density due to predation are un- 
likely because most sampled urchins were large and long-lived (Shears and Babcock 2004). Taken together, these results indicate that predators have only a limited direct, top-down effect on urchin densities. This reflects previous findings that predator presence strongly drives cryptic urchin behavior and reduced grazing activity and the fact that urchins comprise only a fraction (10-30\%) of urchin predator diets. Note that, while predators could conceivably have species-specific effects on urchin predator avoidance $\delta_{U}$ (e.g., greater for slower-moving seastars), previous statistical analyses of patterns in the California Channel Islands did not detect species-specific $\delta_{U}$ (Caselle et al. 2018). We therefore approximate predator avoidance as dependent on total predator density only.

We additionally verify that data on kelp abundance (which reflects both total urchin abundance and per capita grazing activity) can distinguish the direct negative effects of predators on urchin density from indirect negative effects on urchin grazing activity. For this we construct a simple dynamical model of logistically growing urchin abundance $U$ where both mortality and grazing activity $G$ decline with predator density $P$. As with our base model, we assume that grazing activity has negligible effects on urchin density and that predator densities change little on the time scale of urchin population changes, yielding

$$
\begin{aligned}
& \frac{d U}{d t}=r_{U} U(1-U)-U P \\
& \frac{d G}{d t}=U \delta_{A} \exp \left(-P \xi_{P}\right) .
\end{aligned}
$$

We then numerically solve this model for total grazing activity $U$ at steady state (after 50year transient) across levels of $P$ in data (Fig. D1b) and the range of $\xi_{P}$ estimates in our best-fit models. We find that predator avoidance $\left(\xi_{P}>0\right)$ distinctively reduces total urchin grazing compared to when grazing depends on urchin density only (Fig. D1c). 
Figure S3: (a) Urchin densities correspond weakly with reef-scale predator densities and are characterized by lower urchin densities where predators occur, (b) mean sizes of 0-70mm urchins in predator exclosures rarely exceed mean urchin sizes outside predator exclosures, and (c) urchin grazing at steady-state without $\left(\delta_{U}=0\right)$ and with $\left(\delta_{U}>0\right)$ declines in urchin grazing activity with predator density. Blue lines in $(\mathrm{a}, \mathrm{b})$ denote best-fitting splines of predator density effects on each variable. Note that smaller urchin sizes in exclosures (negative values in b) at sites with few predators might arise from competition because urchin densities in exclosures were 1-2 fold greater compared to outside exclosures at all sites.

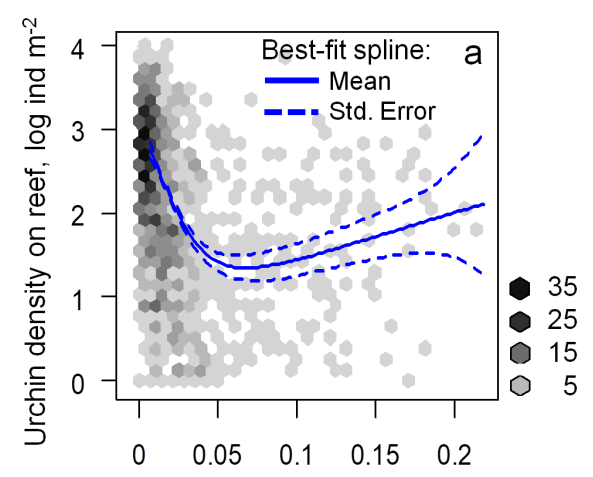

Predator density on reef, ind $\mathrm{m}^{-2}$

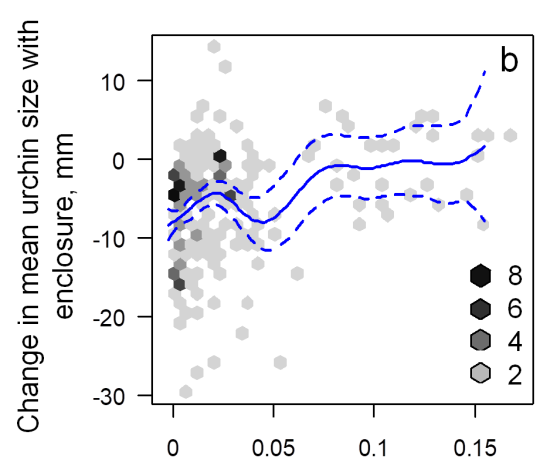

Predator density on reef, ind $\mathrm{m}^{-2}$

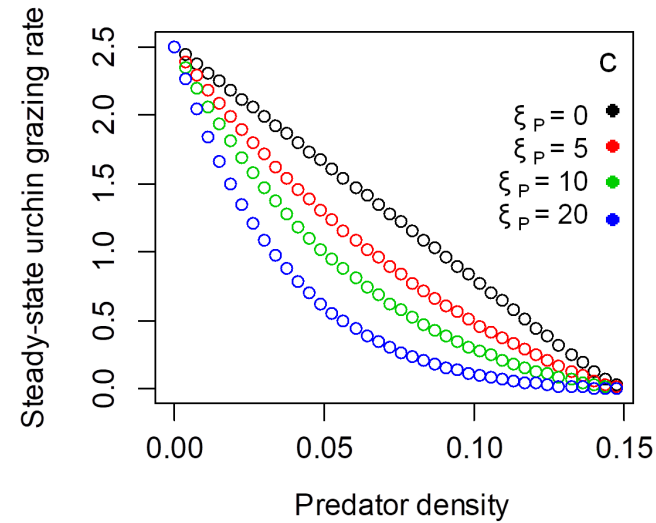

